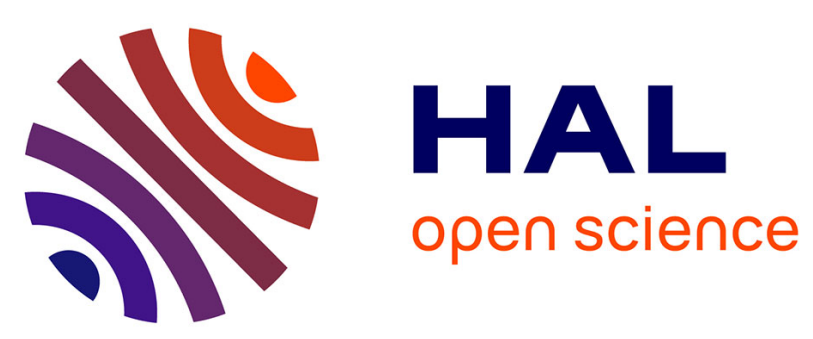

\title{
A single point mutation in ricin A-chain increases toxin degradation and inhibits EDEM1-dependent ER retrotranslocation.
}

Iwona Sokolowska, Sébastien Wälchli, Grzegorz Wegrzyn, Kirsten Sandvig, Monika Slomińska-Wojewódzka

\section{To cite this version:}

Iwona Sokolowska, Sébastien Wälchli, Grzegorz Wegrzyn, Kirsten Sandvig, Monika SlomińskaWojewódzka. A single point mutation in ricin A-chain increases toxin degradation and inhibits EDEM1-dependent ER retrotranslocation.. Biochemical Journal, 2011, 436 (2), pp.371-385. 10.1042/BJ20101493 . hal-00592574

\section{HAL Id: hal-00592574 \\ https://hal.science/hal-00592574}

Submitted on 13 May 2011

HAL is a multi-disciplinary open access archive for the deposit and dissemination of scientific research documents, whether they are published or not. The documents may come from teaching and research institutions in France or abroad, or from public or private research centers.
L'archive ouverte pluridisciplinaire HAL, est destinée au dépôt et à la diffusion de documents scientifiques de niveau recherche, publiés ou non, émanant des établissements d'enseignement et de recherche français ou étrangers, des laboratoires publics ou privés. 


\title{
A single point mutation in ricin A-chain increases toxin degradation and inhibits EDEM1-dependent ER retrotranslocation.
}

\author{
Iwona Sokołowska*, Sébastien Wälchli ${ }^{\dagger}$, Grzegorz Węgrzyn*, Kirsten Sandvig๋, Monika \\ Słomińska-Wojewódzka*§,
}

*Department of Molecular Biology, University of Gdańsk, Gdańsk, Poland, `Department of Immunology, Institute for Cancer Research, The Norwegian Radium Hospital, Oslo University Hospital, Montebello, N-0310 Oslo, Norway, ${ }^{+}$Department of Biochemistry, Institute for Cancer Research, The Norwegian Radium Hospital, Oslo University Hospital, Montebello, N-0310 Oslo, Norway

${ }^{\S}$ Corresponding author: Dr. Monika Słomińska-Wojewódzka, Department of Molecular Biology, University of Gdańsk, Kładki 24, 80-822 Gdańsk, Poland.

Phone: +48 585236395,

Fax: + 48585236424

E-mail:slominsk@biotech.ug.gda.pl

Running title: Intracellular transport of RTA (P250A)

Key words: ricin A-chain, mutation P250A, endosomal-lysosomal degradation, EDEM1, retrotranslocation, endoplamic reticulum

Abbreviations: ER: endoplasmic reticulum, RTA: ricin A-chain RTB: ricin B-chain, P250A: substitution of proline 250 into alanine, RIPs: ribosome-inactivating proteins, EDEM1: ER degradation enhancing $\alpha$-mannosidase I-like protein 1, ERAD: ER-associated protein degradation, NHK: null Hong Kong, mutant variant of $\alpha 1$-antitrypsin, A1AT: $\alpha 1$-antitrypsin, CD: Circular dichroism, DTT: dithiothreitiol, TCA: trichloroacetic acid, CHAPS: 3-[(3cholamidopropyl)dimethylammonio]propane-1-sulfonic acid, HA- hemagglutinin, shRNA: short hairpin RNA, TGN46: trans-Golgi network protein, 46kDa,VLS: vascular leak syndrome, cnx: calnexin, crt: calreticulin. 


\section{SYNOPSIS}

Ricin is a potent plant cytotoxin composed of an A-chain (RTA) connected by a disulfide bond to a cell binding lectin B-chain (RTB). After endocytic uptake, the toxin is transported retrogradely to the endoplasmic reticulum (ER) from where enzymaticaly active RTA is translocated to the cytosol. This transport is promoted by the ER degradation enhancing $\alpha$-mannosidase I-like protein, EDEM1, which is also responsible for directing aberrant proteins for ER-associated protein degradation (ERAD). Ricin A-chain contains a 12-residue hydrophobic C-terminal region which becomes exposed after reduction of ricin in the ER. This region, especially proline 250 , plays a crucial role in ricin cytotoxicity. In this study we introduced a point mutation (P250A) in the hydrophobic region of RTA to study the intracellular transport of the modified toxin. The introduced mutation alters the secondary structure of RTA into a more helical structure. Mutation P250A increases endosomallysosomal degradation of the toxin as well as reduces its transport from the ER to the cytosol. Transport of modified RTA to the cytosol, in contrast to wild-type RTA, appears to be EDEM1independent. Importantly, the interaction between EDEM1 and RTA $250 \mathrm{~A}$ is reduced. This is the first reported evidence that EDEM1 protein recognition might be determined by the structure of the ERAD substrate.

\section{INTRODUCTION}

Ricin, the most toxic member of the ribosome-inactivating proteins (RIPs), accumulates to high levels in the endosperm of Ricinus communis seeds. Cell trafficking of this toxin has been extensively studied due to the variety of medical applications in which it can be used. As an example, ricin has been employed in the construction of immunotoxins which show specific anti-cancer and anti-AIDS activities in vitro and in vivo $[1,2,3,4]$. Ricin is a heterodimeric glycoprotein composed of a RNA-specific $N$-glycosidase A-chain (RTA) connected by a disulfide bond to a cell binding lectin Bchain (RTB). RTA inhibits protein synthesis by enzymatically depurinating a specific adenine residue at the sarcin-ricin loop of the $28 \mathrm{~S}$ rRNA, thereby preventing the binding of elongation factors to the GTPase activation centre of the ribosome [5]. RTB recognizes cell surface glycolipids or glycoproteins having $\beta-1,4$-linked galactose residues. Upon binding to the cell surface, the toxin is taken up by endocytosis and enters early endosomes. From here, the majority of the endocytosed toxin recycles back to the cell surface, starts to be degraded or proceeds to late endosomes and lysosomes where further degradation is conducted $[6,7,8]$. A minor fraction $(\sim 5 \%)$ of ricin is transported from early endosomes to the Golgi apparatus, and from there it is further transported retrogradely to the endoplasmic reticulum (ER). In the ER, the disulfide bond of the holotoxin is reduced to liberate RTA. Upon A and B chain dissociation, a 12-amino-acid (Val245 to Val256) hydrophobic region of the ricin A-chain, which is hidden in the holotoxin, becomes exposed. It has been demonstrated that substitution of proline 250 into alanine (P250A) in this region results in a dramatic decrease in RTA $_{\mathrm{P} 250 \mathrm{~A}}$ cytotoxicity in Vero cells [9]. It is possible that exposure of the RTA hydrophobic region in the ER triggers an interaction between ricin A-chain and membranes, ER chaperones or even ER translocons. Partial unfolding of RTA renders it competent to cross the ER membrane in a similar manner as misfolded ER proteins that are dispatched by proteasomal degradation via the ERassociated degradation (ERAD) pathway [10,11]. Retrotranslocation of RTA from the ER to the cytosol is believed to occur via the Sec61p translocon [12] with assistance of an ER chaperone, ER degradation enhancing $\alpha$-mannosidase I like protein 1, EDEM1 [13]. In the cytosol RTA must refold into its biologically active conformation to inactivate the ribosomes. It has been demonstrated that Hsc70 and Hsp90 cytosolic chaperone machines are involved in RTA folding after retrotranslocation to the cytosol [14]. There is evidence suggesting that RTA can partially disconnect from the ERAD pathway by virtue of its low lysine content [15].

ERAD is a component of the protein quality control system ensuring that misfolded ER proteins are recognized and targeted for degradation. EDEM1 accelerates ERAD of misfolded glycoproteins; its overexpression results in faster release of folding-incompetent proteins from the calnexin cycle and earlier onset of their degradation, whereas EDEM1 down-regulation delays ERAD by prolonging folding attempts $[16,17]$. It has been demonstrated that EDEM1 dependent disposal of 
glycoprotein is regulated by accelerating substrate demannosylation by this protein. EDEM1 removes mannose residues from branch $\mathrm{A}$ and $\mathrm{C}$ of glycoproteins, thereby preventing their re-glucosylation and return of folding-incompetent proteins to the calnexin chaperone system [18, 19]. Moreover, it was shown that EDEM1 accelerates ERAD by inhibiting the formation of disulfide-bonded dimers [20] or covalent aggregates upon release of terminally misfolded ERAD candidates from calnexin [18]. Nonglycan-mediated interaction of EDEM1 and protein substrates has also been reported for: the protein toxin ricin [13]; NHK, mutant variant of $\alpha 1$-antitrypsin (A1AT) [21] and mutant P23H rod opsin [22]. Despite the suggestions that EDEM1 recognizes both glycans and putative misfolded regions of aberrant proteins, little is known about the general mechanisms of substrate recognition by EDEM1 and sorting to the ERAD pathway. This knowledge is crucial in understanding the quality control system operating in the ER, knowledge that may give a better understanding of a broad variety of human diseases caused by defective protein folding or trafficking.

In this study, we produced ricin with a point mutation in the hydrophobic region of RTA (P250A) in order to investigate the effect of this mutation on vesicular transport of ricin, its retrotranslocation from the ER to the cytosol and the interaction between EDEM 1 and RTA $250 \mathrm{~A}$. The P250A mutation alters the secondary structure of the toxin which results in a more helical structure of the protein. We have demonstrated that modified ricin is more extensively degraded in endosomes/lysosomes than the wild-type protein; moreover, we show here that a smaller fraction of P250A ricin is retrotranslocated from the ER to the cytosol when compared to its wild-type counterpart. Importantly, our study revealed that in contrast to wild-type ricin, retrotranslocation of the ricin P250A mutant to the cytosol is EDEM1-independent. Pull-down and coimmunoprecipitation experiments showed that the interaction between EDEM1 and RTA $\mathrm{P}_{\mathrm{P} 250 \mathrm{~A}}$ was significantly decreased. The implications of these findings for medical applications involving ricin as well as for our understanding of ERAD are discussed.

\section{EXPERIMENTAL}

\section{Materials}

Ricin B-chain was obtained from Vector Labs (Burlingame, CA), HEPES, $\alpha$-lactose monohydrate, trypsin, proteinase $\mathrm{K}$, pronase, bafilomycin $\mathrm{A} 1$, brefeldin $\mathrm{A}$, lactacystin, pepstatin $\mathrm{A}$, CA074 methyl ester and digitonin came from Sigma-Aldrich (St.Louis, MO). $\left[{ }^{3}\right.$ H]Leucine was purchased from GE Healthcare (Princeton, NJ), $\mathrm{Na}_{2}{ }^{35} \mathrm{SO}_{4}$ came from Hartmann Analytic (Braunschweig, Germany), whereas $\mathrm{Na}^{-125}$ I from DuPont (Brussels, Belgium). The mouse monoclonal anti-HA antibodies were obtained from Covance Research Products (Denver, CO), rabbit anti-Ricinus Communis-Lectin came from Sigma-Aldrich (St.Louis, MO), whereas mouse monoclonal anti-ricin A-chain and sheep anti-TGN46 were purchased from Serotec (Oxford, UK). The rabbit anti-His antibodies came from Santa Cruz Biotechnology (Santa Cruz, CA). The mouse anti-calnexin (BD Biosciences, Palo Alto, CA), anti-calreticulin (BioSite, San Diego, CA) and anti- $\alpha$-tubulin (SigmaAldrich) were used in Western blots. The secondary anti-rabbit HRP and anti-mouse HRP antibodies, were obtained from Sigma-Aldrich, whereas anti-rabbit Alexa555 and anti-sheep Cy-2 were obtained from Jackson laboratories (Bar Harbour, MA).

\section{Cell culture}

Human Embryonic Kidney 293 (HEK293) and African green monkey kidney (Vero) cells were grown under 5\% $\mathrm{CO}_{2}$ in DMEM (Invitrogen, Carlsbad, CA) supplemented with $10 \%$ fetal bovine serum (FBS) (PAA, Pasching, Austria), $25 \mathrm{U} / \mathrm{ml}$ penicillin, and $25 \mu \mathrm{g} / \mathrm{ml}$ streptomycin (all from Invitrogen) in a $37^{\circ} \mathrm{C}$ incubator.

\section{Cloning, mutagenesis, cDNA constructs and transfections}

Ricin A was amplified from pRA (a kind gift from Prof. Sjur Olsnes (Oslo, Norway), [23]. Detailed cloning and mutagenesis are described in the online supplementary data.

cDNA encoding the mouse EDEM fused to a hemagglutinin (HA) tag in the pCMV-SPORT2 vector was a kind gift from Prof. Nagata and Dr. Hosokawa (Kyoto, Japan). For details of the cloning refer to Hosokawa [24]. 
HEK293 cells were transiently transfected with FuGENE ${ }^{\text {TM }}$ transfection reagent (Roche Diagnostics, Basel, Switzerland) according to the manufacturer's procedure or TurboFect (Fermatas, Vilnius, Lithuania).

\section{Purification of ricin A-chain proteins and reconstitution with ricin B-chain}

RTA His-tag and modified P250A RTA His-tag were expressed in E. coli Rosetta cells (Merck) and purified using Ni-NTA agarose beads (Qiagen, Germantown, MD) according to the manufacturer's manual. The eluate was finally dialysed over night in PBS.

Ricin A-chain sulf-1 and mutant P250A ricin A-chain sulf-1 fused to maltose binding protein (MBP) were applied to a column with amylose resin and purified as previously described [23]. Free wild-type RTA and RTA $A_{\mathrm{P} 250 \mathrm{~A}}$ were cleaved off with factor Xa (New England Biolabs, Ipswich, MA). For further purification, wild-type RTA and RTA P250A $_{\text {p }}$ proteins were applied on a MonoS column (GE Healthcare) and purified using GE Pharmacia Acta Purifier (GE Healthcare). $25 \mathrm{mM}$ phosphate buffer, pH 6.5 was used as the column equilibrating buffer and the wash buffer, proteins were eluted with $0-500 \mathrm{mM}$ $\mathrm{NaCl}$ gradient, and the fractions containing wild-type RTA or RTA $\mathrm{P}_{250 \mathrm{~A}}$ were identified by Coomassiestained SDS/PAGE. Purified wild-type ricin A-chain and mutant P250A were mixed with the ricin Bchain and dialyzed extensively against PBS to remove reducing agents.

\section{Protease Digestion Assay}

$500 \mathrm{ng}$ of RTA or RTA $\mathrm{P}_{250 \mathrm{~A}}$ were incubated with increasing concentrations of trypsin (0-100 $\mu \mathrm{g} / \mathrm{ml})$ in NaCl$/ \mathrm{P}_{\mathrm{i}}\left(137 \mathrm{mM} \mathrm{NaCl}, 2.7 \mathrm{mM} \mathrm{KCl}, 10 \mathrm{mM} \mathrm{Na}_{2} \mathrm{HPO}_{4}, 1.8 \mathrm{mM} \mathrm{KH}_{2} \mathrm{PO}_{4}, \mathrm{pH} 7.4\right)$ at $37^{\circ} \mathrm{C}$ for $15 \mathrm{~min}$ and then visualized by SDS/PAGE and Coomassie Blue staining. For proteinase $\mathrm{K}$ digestion, $500 \mathrm{ng}$ of RTA or RTA $\mathrm{P} 250 \mathrm{~A}$ were incubated with the protease at a final concentration of 0.25 $\mathrm{mg} / \mathrm{ml}$ or $0.5 \mathrm{mg} / \mathrm{ml}$ in a buffer containing $20 \mathrm{mM}$ Tris- $\mathrm{HCl}, \mathrm{pH} 8.0,100 \mathrm{mM} \mathrm{NaCl}$, at $0^{\circ} \mathrm{C}$ for $40 \mathrm{~min}$. Proteins were precipitated with cold $10 \%$ trichloroacetic acid, washed with $100 \%$ acetone and visualized by SDS/PAGE and Coomassie Blue staining. Pronase digestion was performed at $40^{\circ} \mathrm{C}$ for $20 \mathrm{~min}$ in a buffer containing $0.1 \mathrm{M}$ Tris- $\mathrm{HCl}, \mathrm{pH} 5.5$ or 6.5 and $0.5 \%$ SDS with increasing concentrations of the protease $(0-1.5 \mathrm{mg} / \mathrm{ml})$, inactivation of the protease was done at $80^{\circ} \mathrm{C}$ for $10 \mathrm{~min}$. Proteins were visualized by SDS/PAGE and Coomassie Blue staining.

\section{The interchain disulfide bond stability}

An investigation of disulfide bond stability was performed according to the previously published protocol [9].

\section{Circular dichroism}

Far-UV CD was measured on Jasco J-815 spectrapolarimeter (Jasco, Tokyo, Japan). Experiments were performed in $25 \mathrm{mM}$ phosphate buffer, pH 6.5 using a 1-mm-path length cuvette. The concentration of the protein solutions were $30 \mu \mathrm{g} / \mathrm{ml}$. Spectra recorded from 190 to $240 \mathrm{~nm}$ with 1$\mathrm{nm}$ step size were averaged from three accumulations and were corrected against the buffer. Secondary structure analysis of RTA and $\mathrm{RTA}_{\mathrm{P} 250 \mathrm{~A}}$ were performed by using DichroWeb [25] with analysis programmes SELCON3 and CDSSTR. Unfolded RTA P250A was prepared by incubation of RTA P250A (30 $\mu \mathrm{g} / \mathrm{ml})$ at $65^{\circ} \mathrm{C}$ for $20 \mathrm{~min}$ in $25 \mathrm{mM}$ phosphate buffer, $\mathrm{pH} 6.5$.

\section{Measurements of protein synthesis}

HEK 293 cells or Vero cells were washed in leucine free Hepes-buffered medium and incubated with the same type of medium with different concentrations of wild-type or mutant P250A ricin for 3 hours or 12 hours. Optionally, the cells were preincubated with lactacystin for 30 minutes before toxins were added. The concentration of lactacystin is indicated in the figure legend (Figure 2). The cells were then incubated in leucine free medium supplemented with $1 \mu \mathrm{Ci} / \mathrm{ml}\left[{ }^{3} \mathrm{H}\right]$ leucine for 20 minutes or 2 hours at $37^{\circ} \mathrm{C}$. Cells were extracted with $5 \%$ trichloroacetic acid (TCA) for 20 minutes, followed by a wash (5 minutes) in 5\% TCA and subsequently dissolved in $0.1 \mathrm{KOH}$. The cellassociated radioactivity was measured. The results are expressed in percent of $\left[{ }^{3} \mathrm{H}\right]$ leucine incorporated in cells incubated without toxin. Deviations between duplicates did not vary by more than $10 \%$. 


\section{Sulfation of wild-type ricin sulf-1 and mutant P250A and permeabilisation of cells}

Sulfation of wild-type ricin sulf-1 and mutant P250A and permeabilisation of cells were performed according to the previously published protocol [13]. Details of this method as well as western -blot analysis of RTA are described in the online supplementary data.

\section{Measurements of binding, endocytosis and degradation of wild-type ricin and mutant P250A}

Ricin was ${ }^{125}$ I-labeled according to [26], to a specific activity of $3 \times 10^{4}-5 \times 10^{4} \mathrm{cpm} / \mathrm{ng}$. Methods used to measure the binding and endocytosis of wild-type and mutant P250A ricin are described in the online supplementary data.

For degradation measurement, cells were incubated with or without bafilomycin A1 $(0.1 \mu \mathrm{M})$ for 30 min, then ${ }^{125}$ I-labeled wild-type ricin or mutant P250A were added and incubation was continued for additional $15 \mathrm{~min}$. After this, the cells were washed with Hepes medium containing $0.1 \mathrm{M}$ lactose: 15 min incubation and three rapid washes. To determine the degradation of the toxin, incubation was continued for the next 3 hours with or without bafilomycin A1 $(0.1 \mu \mathrm{M})$. Degradation of wild-type ricin and mutant P250A was measured as the amount of radioactivity that could not be precipitated by TCA. In a second experiment, cells were treated either with bafilomycin A1, pepstatin A, CA07 methyl ester, or a combination of pepstatin A and CA074 methyl ester, for 30 minutes, and then incubated with unlabeled wild-type ricin or mutant P250A for 3 hours. To determine the total amount of ricin remaining in the cells after degradation, Western blot with anti-RTA antibodies was performed. Concentrations of inhibitors are indicated in the figure legend (Figure 5).

\section{Confocal fluorescence microscopy}

HEK293 cells were grown on coverslips and incubated with wild-type or P250A ricin for 30 min or 3 hours. The cells were then incubated twice $(5 \mathrm{~min})$ with a $0.1 \mathrm{M}$ lactose solution at $37^{\circ} \mathrm{C}$, then washed once with PBS, and fixed in 3\% paraformaldehyde (PFA, Sigma-Aldrich). Cells were then permeabilised in $0.1 \%$ Triton X-100 and blocked in 5\% FCS before labeling with rabbit anti-ricin together with sheep anti-TGN46 and treated with the appropriate secondary antibodies. DRAQ5 (Alexis Biochemicals, San Diego, CA) was used to stain the nuclei. The cells were mounted in Mowiol (Molecular Probes, Eugene, OR) and examined with a laser scanning confocal microscope LSM 510 META (Carl Zeiss, Jena, Germany). Images were prepared with the LSM Image Browser software (Carl Zeiss) and analysed by the JaCoP plugin [27] in the ImageJ software. Mander's coefficient was used for reporting co-localisation between ricin and TGN46. Manders' co-efficient ranges from 0 to 1 , corresponding to non-overlapping images and $100 \%$ co-localisation between the two images respectively.

\section{Measurements of the amount of wild-type ricin and mutant P250A recycled back to the cell surface}

Cells were incubated with ${ }^{125}$ I-labeled wild-type ricin or mutant P250A $(\sim 100 \mathrm{ng} / \mathrm{ml})$ at $37^{\circ} \mathrm{C}$ for $80 \mathrm{~min}$. Ricin associated with the cell surface was then removed by washing the cells four times with $0.1 \mathrm{M}$ lactose in HEPES at $37^{\circ} \mathrm{C}$ : one long, 15 -min wash, and three rapid washes. The amount of wild-type ricin and mutant P250A recycled back to the cell surface was measured after a $40 \mathrm{~min}$ incubation in the presence of $1 \mathrm{mM}$ lactose to prevent rebinding of recycled ricin to the cell surface. The TCA precipitation and non-precipitable radioactivity in the last incubation medium was measured. The obtained data were compared with the amount of endocytosed ricin.

\section{His-tag pull-down assay}

HEK 293 cells ( $1 \times 10^{5} /$ plate) were seeded in $6 \mathrm{~cm}$ plates and transfected with either EDEM1HA cDNA or an empty vector. Three days post transfection cells were lysed (lysis buffer: $50 \mathrm{mM}$ Hepes, $\mathrm{pH} 7.5 ; 150 \mathrm{mM} \mathrm{NaCl} ; 10 \%$ glycerol and 1\% Triton X-100) in the presence of a protease inhibitor mixture (Roche Diagnostics) and sonicated (5, 20\% output). His-tag fusion proteins: wildtype RTA or mutant P250A RTA $(0.5 \mu \mathrm{g})$ were incubated at $37^{\circ} \mathrm{C}$ for $2 \mathrm{~h}$ with lysates from cells transfected with the indicated constructs and then incubated with Ni-NTA agarose beads (Qiagen). Beads were washed three times with lysis buffer supplemented with $30 \mathrm{mM}$ imidazole and resuspended into a SDS-PAGE sample buffer. Amounts of toxin-bound EDEM1-HA were detected after Western blot with anti-HA antibodies. Signal intensities of the bands were quantified using 
ImageQuant 5.0 software (GE Healthcare). Membranes were re-probed with anti-His or anti-RTA antibodies to confirm equal amounts of RTA-His and RTA $\mathrm{P}_{\mathrm{P} 250 \mathrm{~A}}-\mathrm{His}$ used in the experiments.

\section{Co-immunoprecipitation assay}

EDEM1-transfected cells or cells transfected with an empty vector were incubated with 80 $\mathrm{ng} / \mathrm{ml}$ wild-type ricin or mutant $\mathrm{P} 250 \mathrm{~A}$ for 3 hours, washed with $0.1 \mathrm{M}$ lactose solution at $37^{\circ} \mathrm{C}$, followed by a wash with cold Hepes buffered saline (HBS; $20 \mathrm{mM}$ Hepes, $150 \mathrm{mM} \mathrm{NaCl}, \mathrm{pH}$ 6.8) and lysed in a buffer containing 2\% CHAPS in HBS pH 6.8, $20 \mathrm{mM}$ N-ethylmalemide and protease inhibitor mixture (Roche Diagnostics). The supernatants were centrifuged to remove cell debris and nuclei for 10’000g. Co-immunoprecipitation assay was performed as described previously [13]. Signal intensities of the bands were quantified using ImageQuant 5.0 software (GE Healthcare). For the control of equal amount of EDEM1-HA in the probes, the same membranes were re-probed with antiHA antibodies.

\section{Statistics}

All experiments were performed independently at least three times. Values of 3 or more parallels were given as a mean \pm standard deviation (s.d.). A $p$ value of 0.05 or less was considered to be statistically significant and determined by the Student's $t$-test or ANOVA tests.

\section{RESULTS}

\section{Biophysical characteristics of mutant P250A RTA}

To investigate the significance of the C-terminal hydrophobic region of the ricin A-chain on intracellular transport of the toxin, we produced a mutated form of RTA containing an alanine substitution at amino acid position 250 to replace the naturally occurring proline residue (referred as P250A, see Materials and Methods).

To characterize the correct folding and overall stability of RTA $\mathrm{P}_{\mathrm{P} 250 \mathrm{~A}}$, its sensitivity to proteases was compared to that of wild-type ricin. Digestion patterns for the ricin P250A mutant and wild-type counterpart were the same for both trypsin (Figure 1A) and proteinase K (data not shown) confirming equal in vitro stability of mutant P250A and the wild-type protein. Secondary structure of RTA $250 \mathrm{~A}$ was examined by circular dichroism (CD) and compared with the spectrum for unmodified RTA. The

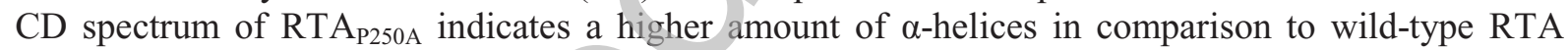
(Figure 1B). This increase in the amount of $\alpha$-helical structures is concomitant with a decrease in $\beta$ sheet structures (DichroWeb analysis, [25]; see Materials and Methods). Wild-type RTA achieves accuracies of 0.19 for helices, 0.32 for beta sheet, 0.21 for turns, 0.21 for unordered structures, while P250A RTA has 0.28 for helices, 0.26 for beta sheet, 0.20 for turns, 0.26 for unordered structures. Normalized root mean square deviation (NRMSD) for the measurements was $<0.05$, $\mathrm{R}$ value $<0.1$. Additional CD spectrum for unfolded RTA $\mathrm{P}_{250 \mathrm{~A}}$ is also shown (Figure 1B). Thus, mutation in the hydrophobic region of ricin A-chain slightly changes the secondary structure of RTA by introducing additional $\alpha$-helical structures.

The obtained modified ricin A-chain was reassociated with ricin B-chain to form a holotoxin (RTA $250 \mathrm{~A}:$ RTB) (see Materials and Methods). To ensure that the introduced mutation was not affecting the reduction of the disulfide bond, either by increasing or decreasing the possibility of reductive cleavage, mutant $\mathrm{P} 250 \mathrm{~A}$ and wild-type holotoxin were incubated with increasing amounts of dithiothreitiol (DTT). The results showed no significant difference in the RTA $\mathrm{P}_{250 \mathrm{~A}}$ : RTB reducibility in comparison to wild-type holotoxin (Figure 1C).

\section{The ricin P250A mutant reveals decreased cytotoxicity in Vero and HEK293 cells}

To investigate whether a mutation in the hydrophobic region of RTA influences its cytotoxicity both in Vero and HEK293 cells, cells were incubated with increasing concentrations of wild-type or modified ricin for 12 hours (Figure 2A,B) or for 3 hours (Figure 2C and data not shown for Vero cells) and the protein synthesis was then measured. Data show that the P250A mutation reduces the cytotoxicity of ricin 9-fold $\left(\mathrm{IC}_{50}\right)$ in both cell lines regardless of the incubation time with the toxin. These data reveal a decreased cytotoxic effect of the ricin P250A mutant; moreover, the observed 
effect is not limited to only a single cell line. A lower cytotoxic effect of the modified P250A toxin was also reported previously in Vero cells incubated for 12 hours with ricin [9].

There was a possibility that the observed protection against ricin containing the P250A mutation might be due to the increased proteasomal degradation of the ricin P250A mutant after retrotranslocation to the cytosol. It is known that, despite low lysine contents, ricin is partially degraded by proteasomes and this degradation can be inhibited by lactacystin [12]. In the presence of this proteasomal inhibitor cells were sensitized to both wild-type ricin and mutant P250A (Figure 2D). However, even in the presence of lactacystin, the cells were still 9-fold less sensitive to the P250A mutant than to the wildtype toxin. Thus, these data suggest that the lower cytotoxicity of ricin with a mutation in the hydrophobic region of RTA was not due to an increased degradation of this toxin after retrotranslocation to the cytosol.

Mutation in the hydrophobic region of RTA does not influence the cellular reductive release of ricin A-chain from the holotoxin, but affects the total amount of the holotoxin P250A mutant in the cell

As described above a mutation changing Pro into Ala in the C-terminus of the ricin A-chain does not affect the reduction of holotoxin in vitro. However, we could not exclude the possibility that the release of the RTA P250A mutant from the holotoxin in the ER was affected by this mutation. To examine the degree of RTA release, cells were incubated with wild-type holotoxin or mutant P250A for 3 hours. RTA and the intact toxin were then immunoprecipitated from the cell lysate, separated under non-reducing conditions and analyzed with anti-RTA antibodies (Figure 3A). There was no significant effect of the mutation in the hydrophobic region of RTA on the fraction of A-chain released from the holotoxin (Figure 3A,B). Thus, the mutation substituting proline into alanine at 250 residue of RTA does not have any effect on the in vivo reduction of the disulfide bond connecting the A-and B-chain of the toxin.

Interestingly, there was around 3-fold less holotoxin P250A mutant and released A-chain compared to the amount of wild-type toxin present in the cell (Figure 3A,C). To further investigate the reason for the observed intracellular decrease of RTAP250:RTB, the amounts of wild-type and P250A ricin sulfated in the Golgi complex were examined. For this purpose wild-type ricin sulf- 1 and mutant P250A [23], a modified ricin molecule containing a sulfation site in the A-chain, were used. When cells are incubated with ${ }^{35} \mathrm{SO}_{4}{ }^{2-}$, the A-chain becomes radioactively labeled due to the sulfotransferase in the TGN, and the fate of the ${ }^{35} \mathrm{SO}_{4}{ }^{2-}$-labeled ricin molecule can be studied. As shown in Figure 3D, a decrease in the amount of the sulfated ricin holotoxin P250A mutant was also observed. This decrease was similar, around 3-fold (data not shown), to the observed reduction in the amount of unlabeled P250A ricin (Figure 3A,C). One possible explanation for the reduced amount of sulfated P250A holotoxin in the Golgi complex could be that less P250A ricin is transported to the Golgi complex in comparison to wild-type ricin. Another possibility is that the holotoxin P250A mutant was less efficiently sulfated than wild-type ricin in the TGN. However, since the total amount of the ricin P250A mutant present in the cell was decreased compared to wild-type toxin (Figure 3A,C) and the level of total cellular protein sulfation, both in cells incubated with wild-type and P250A ricin was equal (data not shown), these data strongly suggest that less mutant than wild-type toxin is transported to the Golgi complex.

To further confirm this observation, we investigated by confocal microscopy the localisation of wild-type or P250A ricin together with TGN46 - a marker for the trans-Golgi network. P250A ricin was found to co-localise with TGN46 to a much lower extent than the wild-type protein (Figure 4). This was observed after $30 \mathrm{~min}$ incubation with the toxin as well as after 3 hours. The microscopic data clearly support our biochemical analysis.

\section{Mutation P250A of RTA does not influence the binding and endocytosis of the modified holotoxin, but affects its endosomal-lysosomal degradation}

To further investigate the reason for the reduced intracellular amount of the holotoxin P250A mutant, measurements of binding and endocytosis of RTA $250 \mathrm{~A}: \mathrm{RTB}$ were performed. The total binding of wild-type holotoxin and mutant P250A to the cell surface was studied by measurement of total ${ }^{125}$ I-labeled wild-type and P250A ricin bound to the cell surface (Figure S1A,B) and by measurement of binding of unlabeled toxins using anti-RTA antibodies and visualization by Western 
blot analysis (Figure S1C,D). In both cases, there was no difference in the amount of cell surface bound P250A holotoxin in comparison to the wild-type protein (Figure S1A-D). These data suggest that the point mutation in the hydrophobic region of RTA (P250A) does not affect the binding of $\mathrm{RTA}_{\mathrm{P} 250 \mathrm{~A}}: \mathrm{RTB}$ to the cell surface. The amounts of cell surface bound wild-type and P250A holotoxin were lower at $37^{\circ} \mathrm{C}$ (Figure S1B) than at $0^{\circ} \mathrm{C}$ (Figure S1A), in agreement with earlier findings for HeLa cells [28]. However, temperature did not influence the ratio of cell surface bound modified holotoxin and wild-type protein (Figure S1A,B).

To test whether mutation in the hydrophobic region of RTA affects endocytosis of RTAP250A:RTB, amounts of lactose-resistant wild-type holotoxin and mutant P250A were analyzed. Figure S2A shows that there are no significant differences between the uptake of ${ }^{125}$ I-labeled P250A holotoxin and ${ }^{125} \mathrm{I}-$ labeled wild-type ricin. Furthermore, endocytosis of both wild-type and modified holotoxin was equally strongly reduced when ATP production was blocked by adding 2-deoxyglucose and sodium azide (Figure S2B,C). Together, these data show that the mutation in the hydrophobic region of ricin A-chain does not affect endocytosis of the holotoxin P250A mutant.

To investigate whether endosomal-lysosomal degradation of $\mathrm{RTA}_{\mathrm{P} 250 \mathrm{~A}}: \mathrm{RTB}$ is changed in comparison to wild-type protein, ${ }^{125} \mathrm{I}$-ricin degradation was measured. Figure $5 \mathrm{~A}$ shows that mutation in the hydrophobic region of RTA increases degradation of the holotoxin P250A mutant more than 2-fold when compared to the wild-type protein. Bafilomycin A1, an inhibitor of the vacuolar $\mathrm{H}^{+}$-ATPase [29, 30] decreases degradation of both unmodified ricin and RTA $A_{P 250 A}: R T B$ in HEK 293 cells. This is in agreement with previous observations, showing that ricin degradation takes place in low-pH compartments in HeLa cells [31]. Importantly, the level of degradation of wild-type and P250A holotoxin in the presence of bafilomycin $\mathrm{A} 1$ is almost equal, strongly indicating that the low- $\mathrm{pH}$ dependent degradation machinery is at least partially responsible for the increased ricin P250A mutant degradation. These results were confirmed in the experiments where the total amount of wild-type and $\mathrm{P} 250 \mathrm{~A}$ ricin in cells treated with or without bafilomycin A1 were estimated by Western blot analysis using anti-RTA antibodies. As shown in Figure 5B,C bafilomycin A1 increases intracellular amounts of wild-type ricin and mutant P250A approximately to the same level, strengthening the suggestion that the observed decrease in the amount of the ricin holotoxin P250A mutant in the cell (Figure 3) is caused by increased endosomal-lysosomal degradation of holotoxin containing a mutation in RTA. It has been demonstrated that aspartyl protease cathepsin D and cysteine protease cathepsin B both participate in ricin cleavage [6]. To estimate if these proteases are responsible for increased P250A ricin degradation, specific inhibitors were employed. Pepstatin A is a potent inhibitor of aspartyl proteases including cathepsin D; CA074 methyl ester blocks cysteine cathepsins, especially cathepsin B. Figure 5D-I shows that both types of proteases are involved in ricin P250A degradation. However, it seems that cathepsin B is more important in this process (Figure $5 \mathrm{~F}, \mathrm{G}$ ). In the presence of CA074 methyl ester the level of $\mathrm{P} 250 \mathrm{~A}$ ricin is significantly increased. Combination of pepstatin $\mathrm{A}$ and CA074 methyl ester seems to increase the cellular level of P250A ricin even further (Figure 5H,I), but not much more than in cells treated only with CA074 methyl ester (Figure 5F,G). Thus, mainly cathepsin B is responsible for the endosomal-lysosomal degradation of the ricin holotoxin P250A mutant in the cell.

To study degradation time dependency, the amount of wild-type holotoxin and mutant P250A in the cells were analyzed after 10,30, 45 and 120 minutes incubation with the toxins (Figure 6A,B). Membranes were probed with anti-RTA antibodies and Western blot analysis was performed. As shown in Figure 6A,B the differences between intracellular amounts of wild-type and P250A ricin increase with the time of incubation. Statistical analysis confirmed that the intracellular amount of ricin is dependent on the time and type of ricin (Anova II, time $-\mathrm{F}_{3,72}=24, \mathrm{p}<0.001$; type of ricin $\mathrm{F}_{1,72}=37, \mathrm{p}<0.001$, for both factors $\left.\mathrm{F}_{3,72}=8, \mathrm{p}<0.001\right)$. Moreover, differences between amounts of wild type and $\mathrm{P} 250 \mathrm{~A}$ ricin after indicated times of toxin incubation are statistically significant $(\mathrm{p}<$ 0.001), however differences after 10 min are marginal.

It has been reported previously that proteolytic cleavage of the ricin A-chain and ricin holotoxin takes place mainly in early endosomes, additionally in late endosomes [6, 7]. If degradation of the ricin P250A mutant is principally dependent on endosomal proteases, one could possibly observe differences in the amount of wild-type and P250A ricin recycled back to the cell surface. To analyze recycling, ${ }^{125}$ I-labeled wild-type and mutant P250A ricin were used. The amount of the holotoxin P250A mutant recycled back to the cell surface was significantly decreased in comparison to wild-type 
ricin (Figure 6C). These data support the hypothesis that ricin containing mutation in the RTA could be more extensively degraded in endosomes than wild-type ricin and therefore less P250A mutant is recycled back to the cell surface. This observation also supports the hypothesis that the lower amount of the sulfated holotoxin P250A mutant results from the decreased transport of RTA $250 \mathrm{~A}:$ RTB to the Golgi apparatus, caused by a lower endosomal amount of P250A holotoxin accessible for endosomesto-Golgi transport.

\section{Mutation in the hydrophobic region of RTA affects its retrotranslocation from the ER to the cytosol}

To investigate whether retrotranslocation of RTA from the ER to the cytosol is affected by the mutation in the C-terminal region of the ricin A-chain, transport of the P250A mutant to the cytosol was studied. Cells incubated with wild-type or modified ricin for 3 hours were subjected to permeabilisation with digitonin to separate the cytosolic fraction from the ER membranes. In a control experiment we tested that ER proteins remained in the ER after permeabilisation. We studied the distribution of calnexin, an ER membrane protein and calreticulin, a soluble ER protein. As shown in Figure $7 \mathrm{H}$, these protein markers were not released from the ER to the cytosolic fraction indicating that ER membranes remained intact during digitonin treatment.

Figure 7A,B shows an 8-9 fold reduction in the amount of modified RTA present in the cytosol fraction in comparison to wild-type RTA. Approximately 3-fold less efficient retrotranslocation of RTA $_{\mathrm{P} 250 \mathrm{~A}}$ from the ER to the cytosol was observed in comparison to wild-type ricin A-chain (Figure 7C,D). Importantly, the difference in the amount of free wild-type RTA and RTA $A_{P 250 \mathrm{~A}}$ in the ER is not higher than 3-fold (Figure 3A; Figure 7C,E), similarly to differences observed for holotoxin present in the Golgi complex. Considering the fact that the reduction of wild-type and modified holotoxin in the ER is the same (Figure 3A,B), we conclude that the efficiency of the transport of modified RTA from the Golgi complex to the ER is the same as for wild-type ricin. Thus, the mutation in the hydrophobic region of RTA affects its transport from the ER to the cytosol, and the observed decrease in cytosolic RTA P250A can not be explained by reduced transport to the ER.

The difference in the cytoplasmic accumulation of wild-type and P250A RTA is not due to increased proteasomal degradation of RTA $255 \mathrm{~A}$. A proteasomal inhibitor, lactacystin, increases the amounts of both wild-type and modified ricin equally (Figure $7 F, G$ ). These data are consistent with the results of cytotoxicity experiments performed in the presence of lactacystin (Figure 2D).

The combination of a higher degradation level of the ricin P250A mutant in endosomes and the lower retrotranslocation of $\mathrm{RTA}_{\mathrm{P} 250 \mathrm{~A}}$ from the ER to the cytosol might explain the estimated 9-fold lower toxic effect of the holotoxin P250A mutant than of wild-type ricin (Figure 2).

\section{Retrotranslocation of the RTA mutant from the ER to the cytosol is EDEM1-independent}

It has been shown previously that the ER chaperone protein, EDEM1 plays a direct role in ricin transport from the ER to the cytosol [13]. To further investigate the mechanism behind the reduced translocation of the P250A mutant to the cytosol, experiments with EDEM1-transfected cells and cells transfected with siRNA vectors against EDEM1 were performed. Retrotranslocation of the wild-type and RTA P250A mutant was studied in cells permeabilised with digitonin, as described above. Two different vectors expressing short hairpin RNA, shRNA, against both mouse and human EDEM1 were already previously employed [13]. Figure 8C demonstrates a very efficient knock-down of mouse EDEM1 for both constructs. Reduction in the expression of endogenous human EDEM1 was confirmed by real-time RT-PCR, which revealed a 70 to $95 \%$ reduction in the mRNA level of this gene (data not shown).

In cells with reduced amounts of EDEM1, the level of wild-type RTA present in the cytosol was decreased (Figure 8A,B), in agreement with earlier findings [13]. This confirms a direct role of EDEM1 in RTA transport to the cytosol. Importantly, the transport of the RTA P250A mutant from the ER to the cytosol seems to be EDEM1-independent, as retrotranslocation assays showed no significant differences in the cytosolic amount of RTA $\mathrm{P} 250 \mathrm{~A}_{\text {in }}$ in cells with reduced amounts of EDEM1 in comparison to cells transfected with an empty control vector (Figure 8A,B).

To determine whether the results from the retrotranslocation assays correspond to the inhibition of protein synthesis caused by the translocated toxin, control cells and cells transfected with siRNA vectors against EDEM1 were incubated with increasing concentrations of wild-type ricin or mutant 
P250A. We observed $\sim 2$-fold protection (statistically significant, $\mathrm{p}<0.001$ ) of siRNA transfected cells against wild-type ricin in comparison to control cells and no significant influence of EDEM1 down-regulation on the cytotoxicity of P250A ricin (Figure 8D,E). These results are in agreement with the suggestion that the RTA P250A mutant lacks EDEM1 contribution in the transport to the cytosol. This might explain the observed decrease in the retrotranslocation of $\mathrm{RTA}_{\mathrm{P} 250 \mathrm{~A}}$ from the ER to the cytosol in comparison to wild-type ricin (Figure 7).

Permeabilisation assays in cells with overproduction of EDEM1 revealed a decrease in both wild-type RTA and mutant P250A present in the cytosol, when compared to cells transfected with control cDNA (Figure 9A,B). It was shown previously that high expression of EDEM1 increases ERAD [24] by promoting extraction of misfolded proteins from the calnexin cycle $[24,16]$. Thus, in EDEM1transfected cells the translocon is mainly occupied by misfolded proteins transported to the cytosol for degradation and access of ricin to the translocon might be inhibited. This suggestion was confirmed in experiments with overproduction of model misfolded proteins [13]. EDEM1 promotes ricin A-chain transport from the ER to the cytosol, but retrotranslocation assays showed a decreased amount of RTA present in the cytosol in EDEM1-transfected cells due to ERAD acceleration [13]. Therefore, in cells with high levels of EDEM1, the availability of the translocon might be limited not only for wild-type but also for mutant P250A RTA; despite different influence of EDEM1 on RTA and RTAP250A retrotranslocation to the cytosol. In agreement with this idea, we observed protection against both wild-type ricin and mutant P250A in cells with overproduction of EDEM1 (Figure 9C,D).

Together, these data support the hypothesis that mutation in the hydrophobic region of RTA disrupts EDEM1-dependent transport of RTA to the cytosol.

\section{The P250A mutation impairs interaction between EDEM1 and RTA}

It was shown previously that EDEM1 interacts directly with the ricin holotoxin [13]. To study interactions between RTA and EDEM1 and between RTAP250A and EDEM1, we cloned and purified the RTA mutant with His-tag (see Materials and Methods). As shown in Figure 10, EDEM1 interacts with the ricin A-chain. This new finding more precisely characterizes the previously observed interaction between EDEM1 and holotoxin [13]. Interestingly, a significant decrease in RTA $250 \mathrm{~A}$ binding to EDEM1 was observed when compared to wild-type RTA (Figure 10). These data might explain EDEM1-independent transport of RTA $\mathrm{P}_{250 \mathrm{~A}}$ to the cytosol. Importantly, circular dichroism analysis of RTA and RTA $\mathrm{P}_{250 \mathrm{~A}}$ with His-tags confirmed altered secondary structure of RTA $2250 \mathrm{~A}$, presented above (Figure 1B).

Our pull-down assays were confirmed by in vivo experiments. We coimmunoprecipitated wild-type ricin or P250A ricin with anti-HA antibodies from lysates of EDEM1-HA-transfected cells or cells transfected with a control empty vector. As shown in Figure 10C, both types of ricin coimmunoprecipitate with EDEM1. Importantly, much more wild-type ricin immunoprecipitates with EDEM1 in comparison to P250A ricin (Figure 10C,D). The level of interaction between wild-type ricin and EDEM1 and P250A ricin and EDEM1 differs in comparison to pull down assays. This is due to the already decreased amount of P250A reaching the Golgi complex and consequently the ER (Figure 3).

These data additionally confirm that the interaction between P250A ricin and EDEM1 is decreased in comparison to wild-type ricin. Since the P250A mutation slightly changes the conformation of the ricin A-chain into a more helical structure it is likely that the precise structure of an ERAD substrate might determine its recognition by EDEM1.

\section{DISCUSSION}

Increased knowledge about protein toxins from plants and bacteria is important both for the development of new therapeutic strategies and for characterization of basal mechanisms in cell biology. The results presented in this study show that point mutation in the hydrophobic region of the ricin A-chain (P250A) influences endosomal-lysosomal degradation of the toxin as well as ricin Achain retrotranslocation from the ER to the cytosol. Our data indicate that interactions between structurally changed $\mathrm{RTA}_{\mathrm{P} 250 \mathrm{~A}}$ and EDEM1 are impaired. This observation may significantly contribute to the general understanding of the recognition of protein substrates by EDEM1. 
Our data show that mutated P250A ricin is 9-fold less toxic than wild-type ricin to Vero and HEK293 cells. It has been demonstrated previously that the P250A mutant has significantly lower activity than wild-type ricin in Vero cells [9], but the reason behind the reduced cytotoxicity was not investigated. Differences in the activity of P250A and wild-type ricin reported previously [9] were higher than those described in this study. Slightly different cell culture conditions, some variability in protein synthesis measurements (e.g. in this study data for single radioactivity measurement comes from much higher amounts of cells) and different sublines of Vero cells may explain such a discrepancy.

Results from experiments performed in the presence of bafilomycin A, which prevents the acidification of endosomes and lysosomes, suggested an increased endosomal-lysosomal degradation of the mutated P250A holotoxin. Furthermore, the kinetics of degradation suggested that P250A ricin degradation starts already in the endosomes, as previously reported for wild-type ricin [6, 7]. It has been demonstrated that the proteases cathepsin B and cathepsin D are responsible for RTA degradation in early endosomes in macrophages; cathepsin B is responsible for toxin cleavage at both neutral and acidic $\mathrm{pH}[6]$. Our results clearly indicate that cathepsin $\mathrm{B}$ and additionally cathepsin $\mathrm{D}$ are involved in increased P250A ricin degradation. Distinct endosomal proteases appear to be active in different cell types. In our study with HEK293 cells, both wild-type ricin and mutated P250A degradation is at least partially dependent on low $\mathrm{pH}$ since bafilomycin A treatment increased intracellular amounts of both toxins and decreased their degradation.

It was observed previously that addition of the ricin B-chain resulted in the protection of RTA from proteolytic activities of lysosomes and cathepsins [32]. This protective role of RTB is partially responsible for the higher toxicity of immunotoxins containing ricin holotoxin in comparison to immunotoxins containing only RTA. Re-association of $\mathrm{RTA}_{\mathrm{P} 250 \mathrm{~A}}$ with RTB produces a holotoxin with a reducible disulfide bond; produces a toxin that is equally bound to the cell surface and equally endocytosed as wild-type ricin. However, due to the structural changes in the mutated P250A RTA, $\mathrm{RTA}_{\mathrm{P} 250 \mathrm{~A}}: \mathrm{RTB}$ can have altered conformation in comparison to the wild-type holotoxin. This altered conformation or/and localization of RTB in relation to $\mathrm{RTA}_{\mathrm{P} 250 \mathrm{~A}}$ might influence its degradation. It should be noted that, in vitro degradation of RTA and RTA $A_{\mathrm{P} 250 \mathrm{~A}}$ by pronase at either $\mathrm{pH} 5.5$ and 6.5 gives similar degradation patterns (data not shown).

Our results demonstrate that a point mutation (P250A) in the RTA decreases its retrotranslocation from the ER to the cytosol. A lack of EDEM1 contribution in this transport might be partially responsible for the observed effect. EDEM1 promotes RTA retrotranslocation to the cytosol [13], however, this protein may not be the only one which facilitates ricin A-chain transport to the cytosol. In addition to the EDEM1 variant protein [24], EDEM2 and EDEM3 homologs also exist in the ER lumen [33, 34, 35]. Both EDEM2 and EDEM3 could be involved in ricin retrotranslocation. It is also possible that ricin can use not only Sec61p, but also other channels/translocons for its transport to the cytosol. Thus, one can expect that $\mathrm{RTA}_{\mathrm{P} 250 \mathrm{~A}}$ retrotranslocation from the ER to the cytosol might be influenced by additional factors; a lack of the assistance of EDEM1 may not be the only reason for the reduction of $\mathrm{RTA}_{\mathrm{P} 250 \mathrm{~A}}$ transport to the cytosol.

It has been demonstrated that RTA binds directly to the membrane surface; at the physiologically relevant temperature of $37^{\circ} \mathrm{C}$, the membrane-bound ricin A-chain loses some $\alpha$-helical structures undergoing the conformational change that exposes its C-terminal region to the membrane interior [36]. Such insertion into the lipid bilayer might represent an early step in RTA translocation through the ER membrane. It is possible that the P250A mutant possessing an elevated level of $\alpha$-helices is unable to undergo additional conformational changes allowing it to be stably inserted into the ER membrane. This might be another limiting step in P250A RTA retrotranslocation to the cytosol.

EDEM1 substrate recognition and sorting to the ERAD pathway are still poorly defined. It has been proposed that EDEM1 acts either as mannosidase that produces demannosylated glycoproteins or as the receptor that recognizes, binds and directs mannose-trimmed proteins for ERAD by extracting them from the calnexin cycle $[16,17,18,19]$. On the other hand, it has been proposed that EDEM1 substrate recognition might be glycan-independent. EDEM1 directly interacts with non-glycosylated ricin, this interaction is independent of glycans presented on RTB [13]. Hebert and colleagues demonstrated that EDEM1 binding does not require the trimming of substrate glycans or even ERAD substrate glycosylation, thus suggesting that EDEM1 probably recognises misfolded regions of aberrant proteins [21]. Similarly, EDEM1 binding to mutant $\mathrm{P} 23 \mathrm{H}$ rod opsin was independent of 
mannose trimming [22]. In this study we demonstrate that point mutation in the hydrophobic region of the ricin A-chain decreases the interaction between RTA and EDEM1. It has been suggested that EDEM1 interacts with proteins via hydrophobic domains [37]. Hydrophobicity of the mutated P250A C-terminal domain of RTA is not changed dramatically in comparison to wild-type RTA. However, a point mutation in this region changes the secondary structure of RTA into more a helical one. This suggests that protein structure might influence EDEM1-protein substrate recognition. This hypothesis has to be confirmed in further experiments. Understanding the mechanisms of recognition and degradation of misfolded proteins synthesized in the ER is one of the fundamental issues in cell biology.

The potency of the protein toxin ricin can be combined with the specificity of various targeting moieties to yield immunotoxins (ITs) used in cancer therapy. However, a major disadvantage is the dose-limiting toxicity associated with ricin-conjugated ITs, which leads to vascular leak syndrome (VLS). It is characterized by hypoalbuminemia, peripheral edema and pulmonary edema in most severe cases [38]. VLS is caused by RTA, which damages vascular endothelial cells by increasing their permeability in a time-and dose-dependent manner [39]. The exact mechanism by which RTA mediates VLS in vivo remains to be determined, but there is evidence suggesting that direct cytotoxicity of RTA leads to VLS in vivo [39]. Thus, as an alternative, the use of toxins that are less cytotoxic to endothelial cells are proposed. Ricin with a mutated hydrophobic region of RTA seems to be a good candidate for such studies. It is still potent enough to be used in ITs, on the other hand it is possible that VLS caused by this toxin would be strongly limited. The influence of RTA $A_{P 250 \mathrm{~A}}$ on endothelial cell permeability should be determined.

In conclusion, the data presented in this study contribute to our general understanding of ricin intracellular transport and mechanism of the recognition of misfolded proteins in the ER. This knowledge might bring new solutions into therapies of severe human diseases.

\section{ACKNOWLEDGMENTS}

We are grateful to Prof. Kazuhiro Nagata and Dr. Nobuko Hosokawa (Institute for Frontier Medical Sciences, Kyoto University, Japan) for cDNA encoding the mouse EDEM1. We would like to thank Dr. Danuta Augustin-Nowacka (Faculty of Chemistry, University of Gdansk, Poland) for CD measurements and analysis. We are grateful to Dr. Sigrid S. Skånland (Institute of Biochemistry II, Goethe University School of Medicine, University Hospital, Frankfurt, Germany) and to Dr. Anna Herman-Antosiewicz (Department of Molecular Biology, University of Gdansk, Poland) for help in the confocal microscopy images preparation. We would like to thank Dr. Anna Kawiak (Department of Biotechnology, Intercollegiate Faculty of Biotechnology, University of Gdansk, Poland) for critical reading of the manuscript.

\section{FUNDING}

This work was supported by the Ministry of Science and Higher Education (grant 3682/P01/2006/32), Foundation for Polish Science (grant "Homing" HOM/12/2007) and by the University of Gdansk (grant 1480-5-0344-6).

\section{REFERENCES}

1. Vitetta, E. S., and Thorpe, P. E. (1991) Immunotoxins containing ricin or it's A chain. Semin. Cell Biol. 2, 47-58

2. Schnell, R., Borchmann, P., Staak, L. O., Schindler, J., Ghetie, V., Vitetta, E. S. and Engert A. (2003) Clinical evaluation of ricin A-chain immunotoxins in patients with Hodgkin's lymphoma. Ann. Oncol. 14, 729-736 
3. Youn, Y. S., Na, D. H., Yoo, S. D., Song, S. C. and Lee K. C. (2005) Carbohydrate-specifically polyethylene glycol-modified ricin A-chain with improved therapeutic potential. Int. J. Biochem. Cell Biol. 37, 1525-1533

4. Polito, L., Bortolotti, M., Farini, V., Battelli, M. G., Barbieri, L. and Bolognesi A. (2009) Saporin induces multiple death pathways in lymphoma cells with different intensity and timing as compared to ricin. Int. J. Biochem. Cell Biol. 41, 1055-1061

5. Sandvig, K., Lauvrak, S. U. and van Deurs, B. (2005) Host Cell Penetration and Trafficking of Protein Toxins. In Microbial Toxins: Molecular and Cellular Biology (Norfolk, T. P., ed.), pp. 473-469, Horizon Press

6. Blum, J. S., Fiani, M. L. and Stahl, P. D. (1991) Proteolytic cleavage of ricin A chain in endosomal vesicles. J. Biol. Chem. 266, 22091-22095

7. Brech, A., Kjeken, R., Synnes, M., Berg, T., Roos, N. and Prydz K. (1998) Endocytosed ricin and asialoorosomucoid follow different intracellular pathways in hepatocytes. Biochim. Biophys. Acta 1373, 195-208

8. Sandvig, K., and van Deurs, B. (2002) Membrane traffic exploited by protein toxins. Ann. Rev. Cell Biol. 18, 1-14

9. Simpson, J. C., Lord, J. M. and Roberts, L. M. (1995) Point mutations in the hydrophobic Cterminal region of ricin A chain indicate that Pro250 plays a key role in membrane translocation. Eur. J. Biochem. 232, 458-463

10. Romisch, K. (2005) Endoplasmic reticulum-associated degtadation. Annu. Rev. Cell Dev. Biol. 21, 435-456

11. Bukau, B., Weissman, J. and Horwich, A. (2006) Molecular Chaperones and Protein Quality Control. Cell 125, 443-451

12. Wesche, J., Rapak, A. and Olsnes, S. (1999) Dependence of ricin toxicity on translocation of the toxin A-chain from the endoplasmic reticulum to the cytosol. J. Biol. Chem. 274, 34443-34449

13. Slominska-Wojewodzka, M., Gregers, T. F., Wälchli, S. and Sandvig K. (2006) EDEM is involved in retrotranslocation of ricin from the endoplasmic reticulum to the cytosol. Mol. Biol. Cell 17, 1664-1975

14. Spooner, R. A., Hart, P. J., Cook, J. P., Pietroni, P., Rogon, C., Hohfeld, J., Roberts, L. M. and Lord, J. M. (2008) Cytosolic chaperones influence the fate of a toxin dislocated from the endoplasmic reticulum. Proc. Natl. Acad. Sci. USA 105, 17408-17413

15. Deeks, E. D., Cook, J. P., Day, P. J., Smith, D. C., Roberts, L. M. and Lord, J. M.(2002) The low lysine content of ricin A chain reduces the risk of proteolytic degradation after translocation from the endoplasmic reticulum to the cytosol. Biochemistry 41, 3405-3413

16. Molinari, M., Calanca, V., Galli, C., Lucca, P. and Paganetti, P. (2003) Role of EDEM in the release of misfolded glycoproteins from the calnexin cycle. Science 299, 1397-1400

17. Oda, Y., Hosokawa, N., Wada, I and Nagata, K. (2003) EDEM as an acceptor of terminally misfolded glycoproteins released from calnexin. Science 299, 1394-1397

18. Olivari, S., Cali, T., Salo, K. E., Paganetti, P., Ruddock, L. W. and Molinari. M. (2006) EDEM1 regulates ER-associated degradation by accelerating de-mannosylation of folding-defective polypeptides and by inhibiting their covalent aggregation. Biochem. Biophys. Res. Commun. 349, $1278-1284$

19. Hosokawa, N., Tremblay, L. O., Sleno, B., Kamiya, Y., Wada, I., Nagata, K., Kato, K. and Herscovics, A. (2010) EDEM1 accelerates the trimming of a 1,2-linked mannose on the C branch of N-glycans. Glycobiology 20, 567-575

20. Hosokawa, N., Wada, I., Natsuka, Y. and Nagata, K. (2006) EDEM accelerates ERAD by preventing aberrant dimer formation of misfolded $\alpha 1$-antitrypsin. Genes to Cells 11, 465-476

21. Cormier, J. H., Tamura, T., Sunryd, J. C. and Hebert, D. N. (2009) EDEM1 recognition and delivery of misfolded proteins to the SEL1L-containing ERAD complex. Mol. Cell 34, 627-633

22. Kosmaoglou, M., Kanuga, N., Aguila, M., Garriga, P. and Cheetham, M. E. (2009) A dual role for EDEM1 in the processing of rod opsin. J. Cell Sci. 122, 4465-4472

23. Rapak, A., Falnes, P. O. and Olsnes, S. (1997) Retrograde transport of mutant ricin to the endoplasmic reticulum with subsequent translocation to cytosol. Proc. Natl. Acad. Sci. USA 94, $3783-3788$ 
24. Hosokawa, N., Wada, I., Hasegawa, K., Yorihuzi, T., Tremblay, L. O., Herscovics, A. and Nagata K. (2001) A novel ER alpha-mannosidase-like protein accelerates ER-associated degradation. EMBO Rep 2, 415-422

25. Whitmore, L. and Wallace, B. A. (2008) Protein secondary structure analyses from circular dichroism spectroscopy: methods and reference databases. Biopolymers 89, 392- 400

26. Fraker, P. J. and Speck, J. C. Jr. (1978) Protein and cell membrane iodinations with a sparingly soluble chloroamide, 1,3,4,6-tetrachloro-3a,6a-diphrenylglycoluril. Biochem. Biophys. Res. Commun. 80, 849-857

27. Bolte, S. and Cordelieres, F. P. (2006) A guided tour into subcellular colocalization analysis in light microscopy. J Microsc. 224, 213-232

28. Sandvig, K. and Olsnes, S. (1979) Effect of temperature on the uptake, excretion and degradation of abrin and ricin by HeLa cells. Exp. Cell Res. 121, 15-25

29. Bowman, E. J., Siebers, A. and Altendorf, K. (1998) Bafilomycins: a class of inhibitors of membane ATPases from microorganisms, animal cells, and plant cells. Proc. Natl. Acad. Sci. USA 85, 7972-7976

30. Yoshimori, T., Yamamoto, Y., Moriyama, M., Futai, M. and Tashito, Y.(1991) Bafilomycin A1, a specific inhibitor of vacuolar-type $\mathrm{H}(+)$-ATPase, inhibits acidification and protein degradation in lysosomes of cultured cells. J. Biol. Chem. 266, 17707-17712

31. Llorente, A., Rapak, A., Schmid, S. L., van Deurs, B. and Sandvig, K. (1998) Expression of mutant dynamin inhibits toxicity and transport of endocytosed ricin to the Golgi apparatus. J. Cell Biol. 140, 553-563

32. Bilge, A., Howell-Clark, J., Ramakrishnan, S. and Press, O. W. (1994) Degradation of ricin A chain by endosomal and lysosomal enzymes-the protective role of ricin B chain. Ther. Immunol. 1, 197-204

33. Mast, S. W., Diekman, K., Karaveg, K., Davis, A, Sifers, R. N. and Moremen, K. W. (2004) Human EDEM2, a novel homolog of family 47 glycosidases, is involved in ER-associated degradation of glycoproteins. Glycobiology 15, 421-436

34. Olivari, S., Galli, C., Alanen, H., Ruddock, L. and Molinari, M. (2005) A novel stress-induced EDEM variant regulating endoplasmic reticulum-associated glycoprotein degradation. J. Biol. Chem. 280, 2424-2428

35. Hirao, K., Natsuka, Y., Tamura, T., Wada, I., Morito, D., Natsuka, S., Romero, P., Sleno, B., Tremblay, L. O., Herscovics, A., Nagata, K. and Hosokawa, N. (2006) EDEM3, a soluble EDEM homolog, enhances glycoprotein endoplasmic reticulum-associated degradation and mannose trimming. J. Biol. Chem. 281, 9650-9658

36. Mayerhofer, P. U., Cook, J. P., Wahlman, J., Pinheiro, T. J., Moore, K., A., H., Lord, J. M., Johnson, A. E. and Roberts, L. M. (2009) Ricin A chain insertion into endoplasmic reticulum membranes is triggered by a temperature increase to $37^{\circ} \mathrm{C}$. J. Biol. Chem. 284, 10232-1-242

37. Wang, T. and Hebert, D. N. (2003) EDEM an ER quality control receptor. Nat. Struct. Biol. 10, 319-321

38. Vitetta, E. S., Thorpe, P. E. and Uhr, J. W. (1993) Immunotoxins: Magic bullets or misguided missles? Immunol Today 14, 252-259

39. Lindstrom, A. L., Erlandsen, S. L., Kersey, J. H. and Pennell, C. A. (1997) An in vitro model for toxin-mediated vascular leak syndrome: Ricin toxin A chain increases the permability of human endotelial cell monolayers. Blood 90, 2323-2334

\section{FIGURE LEGENDS}

Figure 1 Biochemical characteristics of P250A ricin. (A) Coomasie Blue-stained 12\% SDS/PAGE gels showing the effect of the incubation of 500ng of wild-type ricin A-chain, RTA, and modified ricin A-chain, RTA (P250A), with increasing concentrations of trypsin. (B) Far UV CD spectra of wildtype RTA, wt; RTA $2250 \mathrm{~A}, \mathrm{P} 250 \mathrm{~A}$ and thermally unfolded P250A. The scans were corrected by the subtraction of blanks containing only the buffer. Averaged spectra from three measurements; s.d. $\leq$ $3 \%$. (C) Coomasie Blue-stained 12\% SDS/PAGE gels showing the effect of increasing concentrations of dithriothreitol (DTT) on the reduction of wild-type holotoxin and P250A holotoxin. 
Figure 2 P250A ricin has reduced toxicity to target cells. Effect of increasing concentrations of mutant P250A and wild-type ricin on Vero cells (A) and HEK293 cells incubated with the toxin for 12 hours (B) and for 3 hours (C). Wild-type ricin, wt, (closed circles); modified ricin, P250A, (closed squers). Data with s.d. from five independent experiments. (D) Effect of the proteasomal inhibitor lactacystin $(10 \mu \mathrm{M})$ on the toxicity of wild-type ricin and mutant P250A. Wild-type ricin, wt, (closed circles); wild-type ricin treated with lactacystin, wt Lac, (closed squares); modified ricin, P250A, (open circles); modified ricin treated with lactacystin, P250A Lac, (open squares). Data with s.d. from five independent experiments.

Figure 3 Mutation in the hydrophobic region of RTA does not affect the release of the ricin Achain from the holotoxin, but influences the amount of modified holotoxin in the cell. (A) HEK293 cells after 3 hours incubation with wild-type ricin, wt, or modified ricin, P250A, run on SDS/PAGE under non-reducing conditions. A representative gel after Western blot with anti-RTA antibodies is shown. (B) Calculation of the release of RTA from the holotoxin for wild-type ricin, wt, and modified toxin, P250A. Data with s.d. from five independent experiments. Wt is regarded as the control and is marked as $100 \%$ (C) Calculation of the total amount of wild-type holotoxin, wt, and modified ricin, P250A present in the cell. Data with s.d. from five independent experiments. Wt is regarded as the control and is marked as $100 \%$ (D) Tyrosine sulfated wild-type ricin sulf-1, wt, and modified ricin sulf-1, P250A, in cells after 3 hours incubation with $\mathrm{Na}_{2}^{34} \mathrm{SO}_{4}$ and further $3 \mathrm{~h}$ incubation with the toxins, run on SDS/PAGE under non-reducing conditions. A representative autoradiogram is shown.

Figure 4 P250A ricin co-localises with TGN46 to a lower extent than wild-type ricin. Cells were incubated with wild-type ricin or mutant P250A for $30 \mathrm{~min}(\mathbf{A})$ or $3 \mathrm{~h}(\mathbf{B})$ before the cells were fixed and stained as indicated. DRAQ5 was used to stain the nuclei. Bars, $10 \mu \mathrm{m}$. Co-localisation of wildtype ricin or mutant P250A with TGN46 was measured using the JACoP tool. Bars represent standard deviation; $\mathrm{p}<0.05, \mathrm{n}=15$.

Figure 5 P250A ricin shows increased degradation in low $\mathbf{p H}$ vesicles. (A) Cells were preincubated with (+ baf) or without bafilomycin A1 $(0.1 \mu \mathrm{M}){ }^{125}$ I-labeled wild-type ricin, wt, or modified ${ }^{125} \mathrm{I}$ labeled ricin, P250A, were added. Ricin degradation was measured as described in Materials and Methods. Data with s.d. from five independent experiments. Wt is regarded as the control and is marked as $100 \%$. Other results are relative to this control. Cells were treated with or without bafilomycin A1 $(0.1 \mu \mathrm{M})(\mathbf{B})$, pepstatin A (pep) $(10 \mu \mathrm{g} / \mathrm{ml})(\mathbf{D})$; CA074 methyl ester (CA074-Me) (50 $\mu \mathrm{M})(\mathbf{F})$ or a combination of pepstatin A and CA074 methyl ester (inhibitors) (H) and unlabeled RTA:RTB or RTA $250 \mathrm{~A}:$ RTB. The amount of wild-type and P250A ricin that remain in the cell after degradation was analyzed after SDS-PAGE under non-reducing conditions (see Materials and Methods). Representative membranes after Western blot with anti-RTA antibodies are shown. (C),(E),(G),(I) Data with s.d. from five independent experiments presented in (B), (D), (F), (H) respectively. Wt is regarded as the control and is marked as 1 . Other results are relative to this control.

Figure 6 Differences in the intracellular amount of wild-type ricin and mutant P250A increase with the time of toxin incubation. Lower amount of the ricin P250A mutant is recycled back to the cell surface. (A) Cells were incubated with wild-type ricin, wt, or modified ricin, P250A. Times of incubation at $37^{\circ} \mathrm{C}$ as indicated. SDS-PAGE under non-reducing conditions was performed. A representative membrane after Western blot with anti-RTA antibodies is shown. (B) Data with s.d. from five independent experiments presented in (A). (C) Amount of ${ }^{125}$ I-labeled wild-type, wt, or ${ }^{125} \mathrm{I}$ labeled modified ricin, P250A, recycled back to the cell surface was measured as described in Materials and Methods. Data with s.d. from five independent experiments.

Figure 7 Decreased retrotranslocation of the ricin A-chain P250A mutant from the ER to the cytosol. Cells incubated with wild-type ricin, wt, or modified ricin, P250A, were subjected to permeabilisation (see Materials and Methods). (A) A representative membrane after Western blot with anti-RTA antibodies is shown. SDS/PAGE was performed under reducing conditions. The experiments were done in duplicates. (B) Average data with s.d. from five independent experiments 
presented in (A). Graph shows relative amount of wild-type RTA, wt, and modified RTA, P250A, present in the cytosolic fraction. Wt is marked as 1, amount of P250A is relative to this control. (C) A representative membrane after Western blot with anti-RTA antibodies is shown. SDS/PAGE was performed under non-reducing conditions. The membrane represents RTA present in the ER. (D) Average data with s.d. from five independent experiments presented in (C). Graph shows percentage of wild-type RTA, wt, and modified RTA, P250A, retrotranslocated to the cytosol. (E) Average data with s.d. from five independent experiments presented in (C). Graph shows differences between wildtype RTA, wt, and modified RTA, P250A, present in the ER. Wt is marked as 1, amount of P250A is relative to this control. (F) A representative membrane after Western blot with anti-RTA antibodies is shown. SDS/PAGE was performed under non-reducing conditions. Cells were preincubated with lactacystin $(10 \mu \mathrm{M})$ before addition of ricin. (G) Average data with s.d. from five independent experiments presented in (F). Graph shows relative amount of wild type RTA, wt, and modified RTA, P250A, present in the cytosolic fraction. Amount of wt RTA is marked as 1, other results are relative to this control. Lac-lactacystin. (H) Distribution of the resident ER proteins, calnexin (clx) and calreticulin (crt) after permeabilisation with digitonin. A representative membrane after Western blot with anti-calnexin and anti-calreticulin is shown. Such permeablisation control was performed for experiments presented in Figures 7, 8, 9.

Figure 8 P250A ricin A-chain retrotranslocates in an EDEM1-independent manner, EDEM1 knockdown studies. Cells transfected with siRNA constructs against EDEM1 or with an unspecific siRNA construct (ctrl) incubated with wild-type ricin, wt, or modified ricin, P250A, were subjected to permeabilisation (see Materials and Methods). (A) A representative experiment is shown with siRNA construct number 1 (siRNA1). SDS/PAGE was performed under reducing conditions. (B) Average data with s.d. from five independent experiments with siRNA construct number 1 (siRNA1) and construct number 2 (siRNA2). Graphs show relative amount of wild-type RTA, wt, and modified RTA, P250A, present in the cytosolic fraction. Amounts of wt RTA are marked as 1, other results are relative to this control. (C) The presence of EDEM1-HA was determined by Western blot analysis with anti-HA antibodies. Cells were co-transfected with HA-tagged mouse EDEM1 and siRNA constructs against EDEM1. Membranes were re-probed with anti-tubulin antibodies for equal loading control. (D) Protein synthesis was measured after 12 hours incubation with the toxins (see Materials and Methods). Wild-type ricin, wt, (closed circles); wild-type ricin in siRNA -transfected cells, wt siRNA1 (closed squares); modified ricin, P250A (open circles); modified ricin in siRNA-transfected cells, P250A siRNA1 (open squares). (E) Average data with s.d. from five independent experiments with siRNA construct number 1 (siRNA1) and siRNA construct number 2 (siRNA2). The level of $50 \%$ incorporation of $\left[{ }^{3} \mathrm{H}\right]$ leucine with wild-type ricin, wt, is marked as 1 and the concentration of wt and P250A required to induce a similar inhibition under other conditions are plotted as relative values compared to this control.

Figure 9 P250A ricin A-chain retrotranslocation, EDEM1 overexpression studies. (A) EDEM1transfected cells or cells transfected with an empty control vector (ctrl) incubated with wild-type ricin, wt, or modified ricin, P250A, were subjected to permeabilisation (see Materials and Methods). A representative membrane after Western blot with anti-RTA antibodies is shown. SDS/PAGE was performed under reducing conditions. (B) Average data with s.d. from five independent experiments presented in (A). Graph shows relative amount of wild type RTA, wt, and modified RTA, P250A, present in the cytosolic fraction. Amount of wt RTA is marked as 1, other results are relative to this control. (C) Protein synthesis was measured after 12 hours incubation with toxins (see Materials and Methods). Wild-type ricin, wt, (closed circles); wild-type ricin in EDEM1-transfected cells, wt EDEM1, (closed squares); modified ricin, P250A, (open circles); modified ricin in EDEM1transfected cells, P250A EDEM1, (open squares). A representative experiment is shown. (D) Average data with s.d. from five independent experiments. The level of $50 \%$ incorporation of $\left[{ }^{3} \mathrm{H}\right]$ leucine with wild-type ricin, wt, is marked as 1 and the concentration of wt and P250A required to induce a similar inhibition under other conditions are plotted as relative values compared to this control.

Figure 10 Point mutation P250A in the hydrophobic region of the ricin A-chain impairs interaction between EDEM1 and RTA. (A) Protein interactions were examined by His-tag pull- 


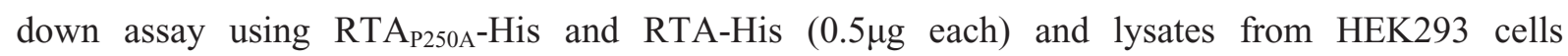
overexpressing EDEM1-HA or cells transfected with an empty control vector, ctrl, (for experimental details see Materials and Methods). Proteins bound to the beads were analyzed by SDS/PAGE and Western blot with anti-HA antibodies (upper panel). The same membranes were re-probed with antiHis or anti-RTA antibodies (middle panel, western-blot with anti-RTA is shown). Whole cell lysates (WCL) analyzed with anti-HA antibodies are shown in the bottom panel. Lines: 1-3 empty vectortransfected cells, ctrl; 4-6 EDEM1-HA-transfected cells, 1 and 4 without toxin; 2 and 5 with RTA-His; 3 and 6 with RTA P250A -His. A representative experiment is shown. (B) Average data from His-tag pull-down with s.d. from five independent experiments. The amount of EDEM1 bound to RTA $A_{\mathrm{P} 250 \mathrm{~A}}$ is relative to the amount of EDEM1 interacting with wild-type RTA marked as 1 . (C) Immunoprecipitation of wild-type ricin or P250A ricin with anti-HA antibodies. Representative example of experiments is shown. SDS-PAGE was performed under non-reducing conditions. Membranes were reprobed with anti-HA antibodies to confirm equal immunoprecipitation.(D) Average data with s.d. from five independent experiments presented in (C). The level of immunoprecipitated wild- type ricin from EDEM1-transfected cells is marked as 1, the level of immunoprecipitated $\mathrm{P} 250 \mathrm{~A}$ ricin is relative to this value. 
A

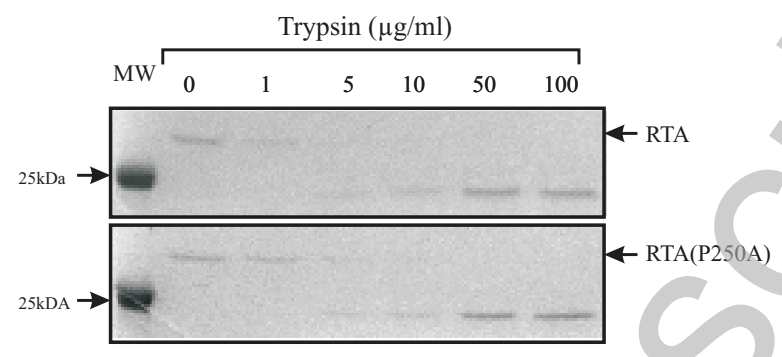

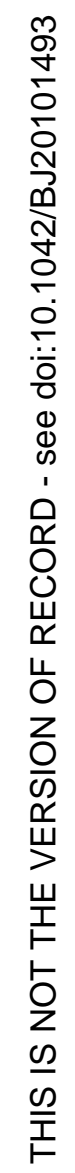

B
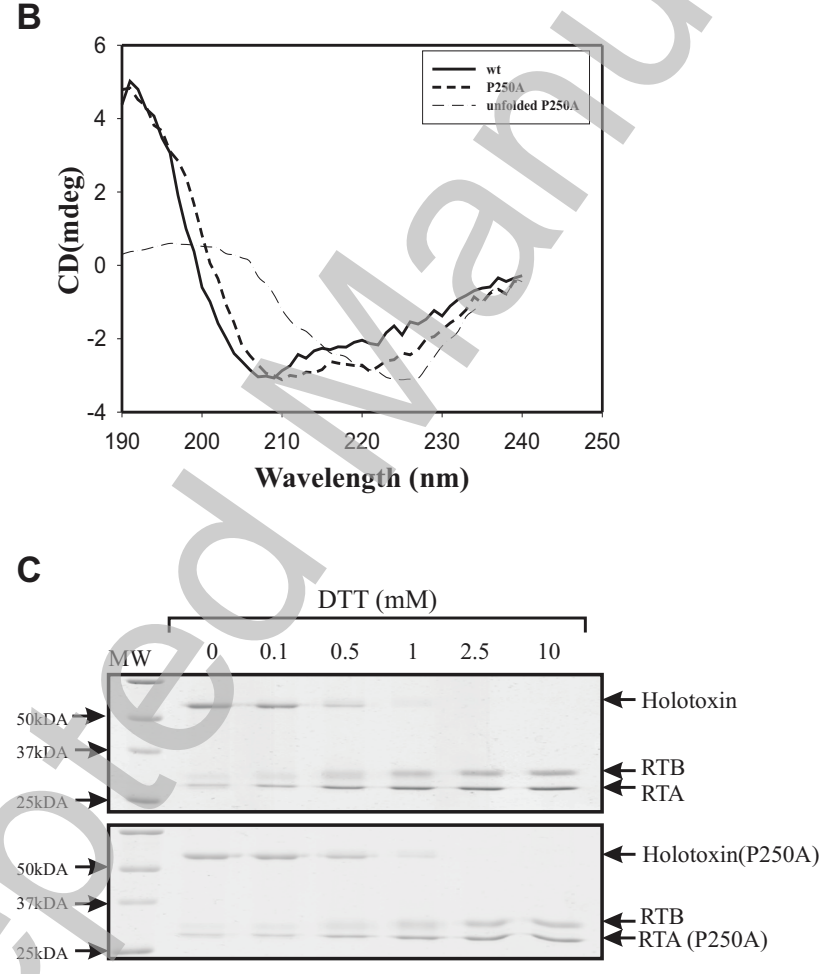

Figure 1

Licenced copy. Copying is not permitted, except with prior permission and as allowed by law. (C) 2011 The Authors Journal compilation (c) 2011 Portland Press Limited 
A

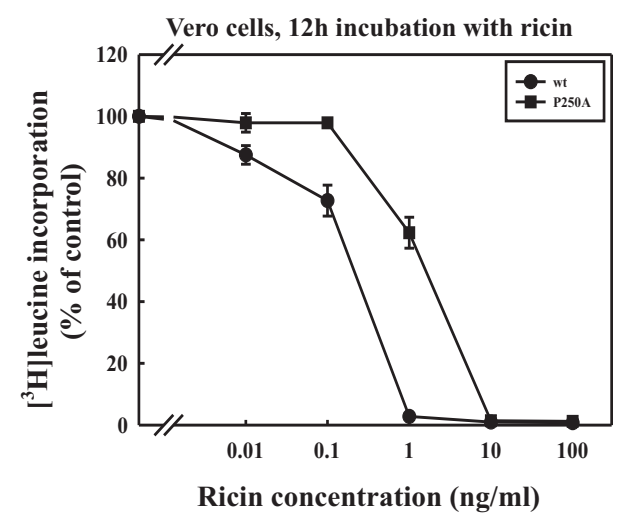

C

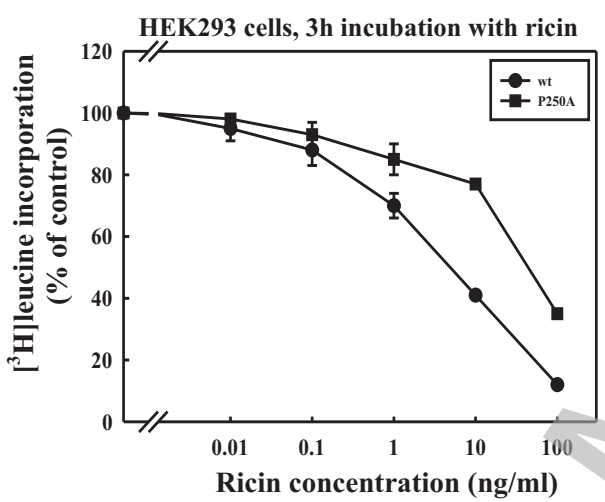

B

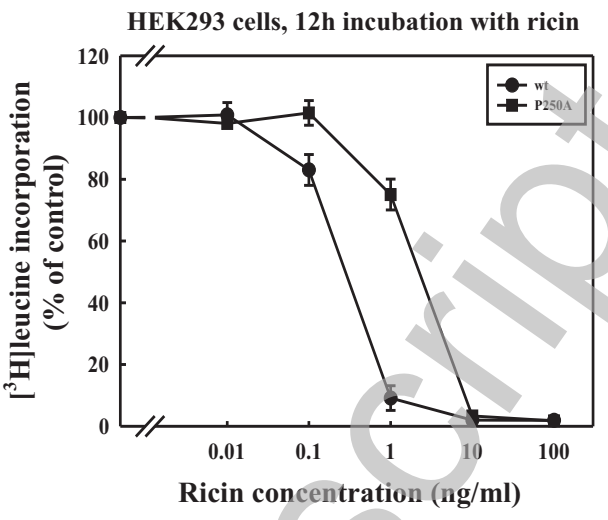

D

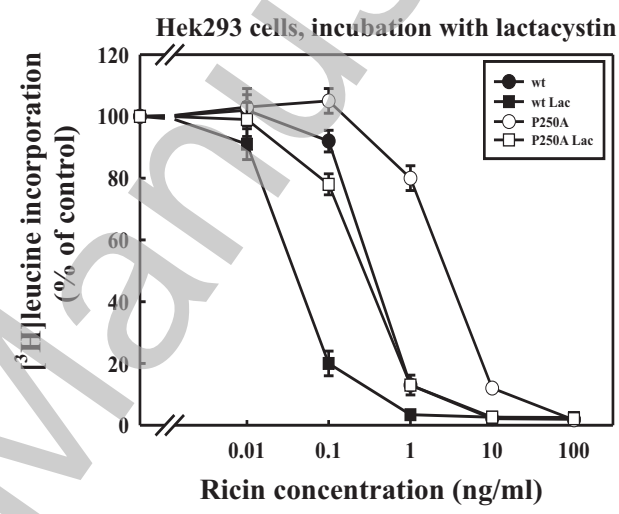

Figure 2

Licenced copy. Copying is not permitted, except with prior permission and as allowed by law. (C) 2011 The Authors Journal compilation (c) 2011 Portland Press Limited 
A

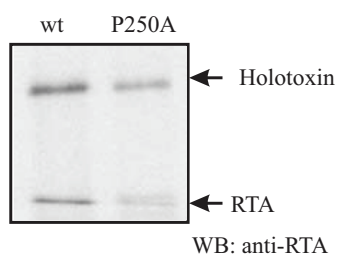

B

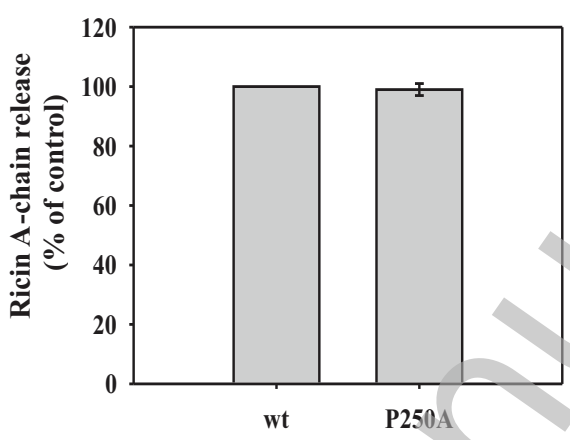

C

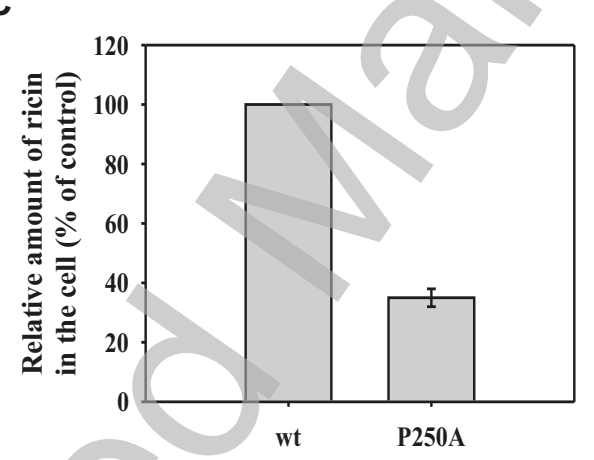

D

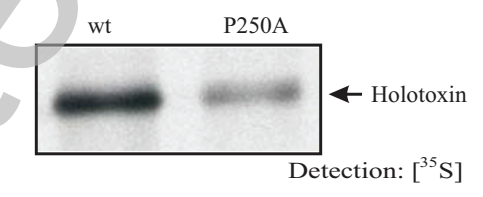

Figure 3 
A

30 min incubation with ricin
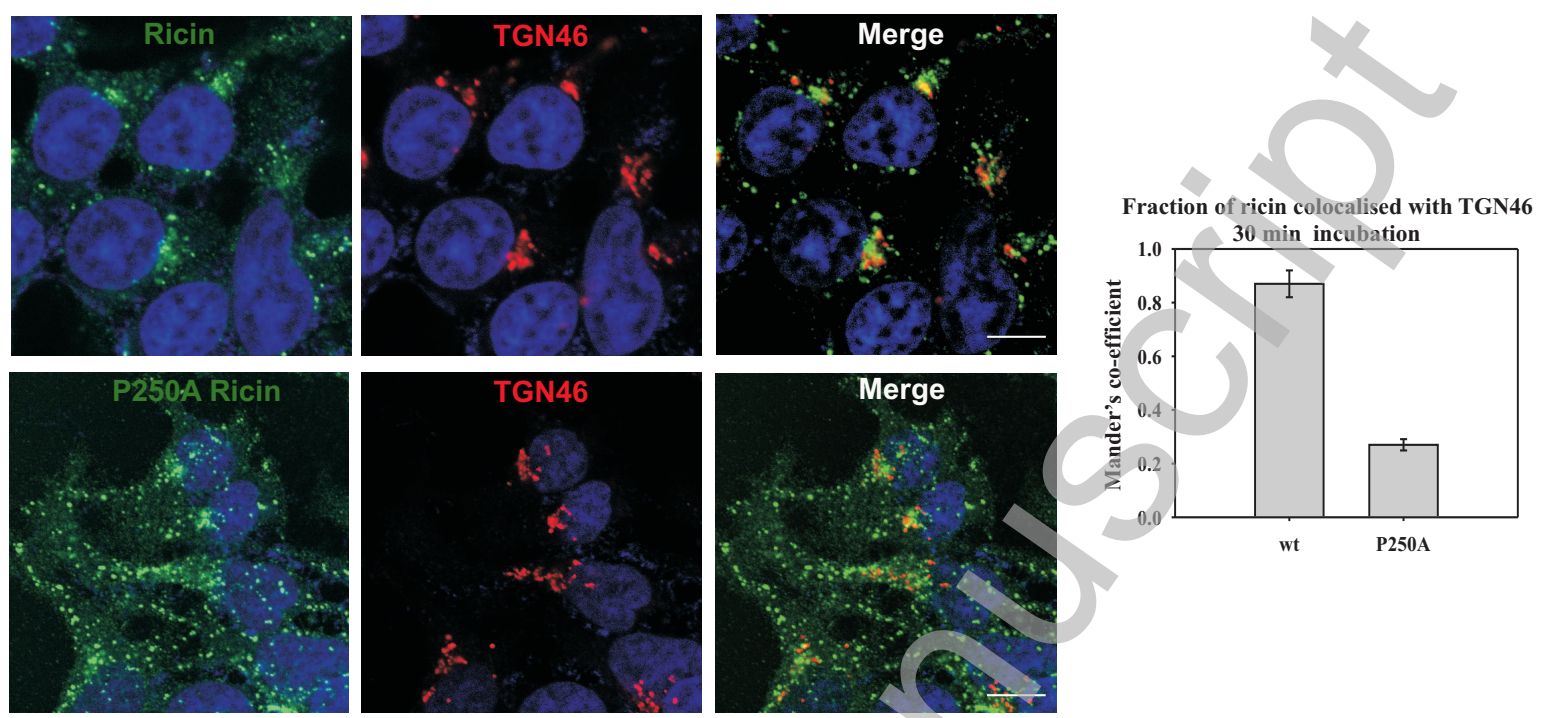

B

3 hours incubation with ricin
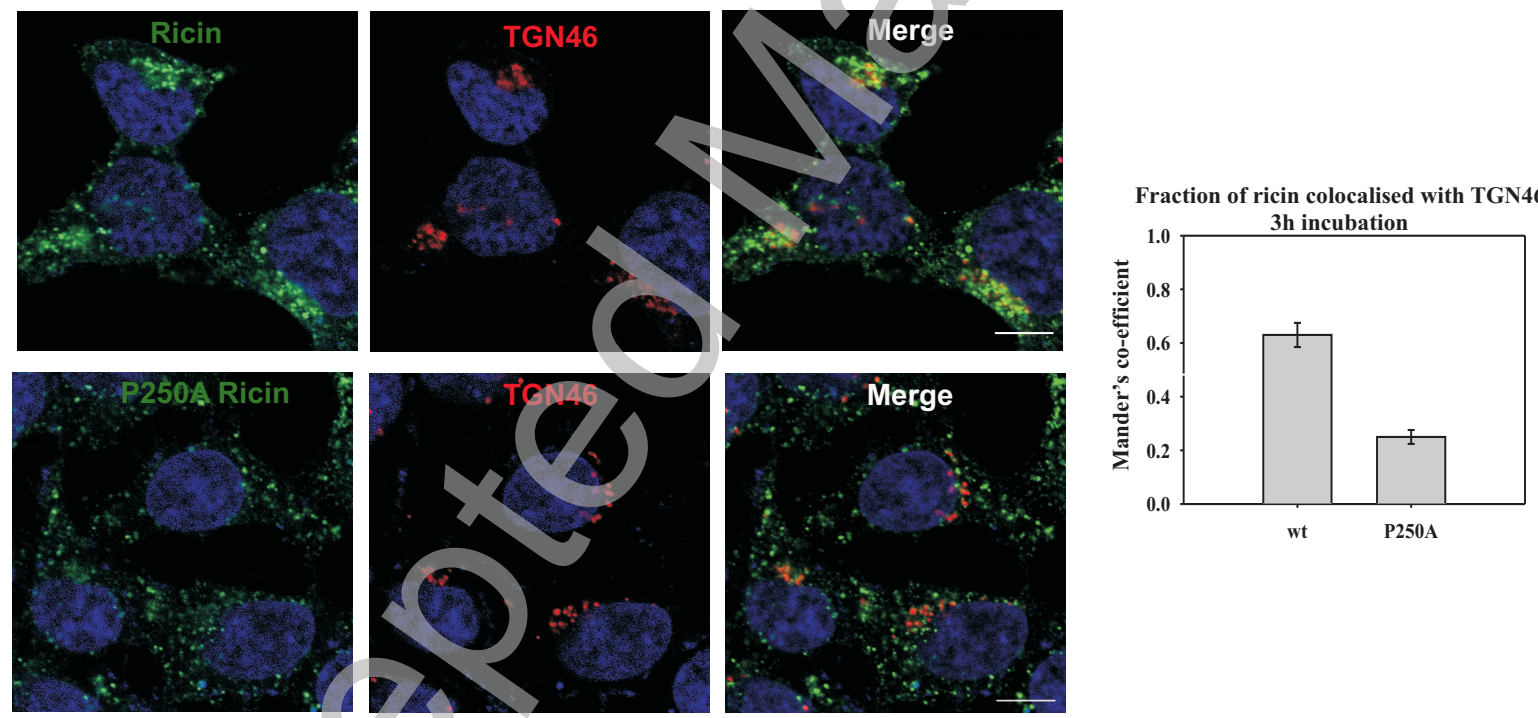

Figure 4

Licenced copy. Copying is not permitted, except with prior permission and as allowed by law. (C) 2011 The Authors Journal compilation (c) 2011 Portland Press Limited 
A

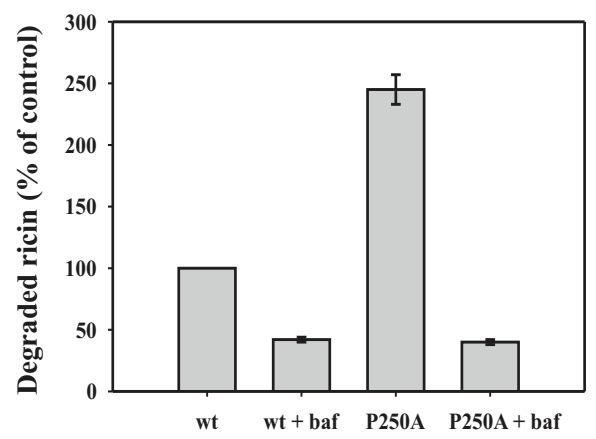

B

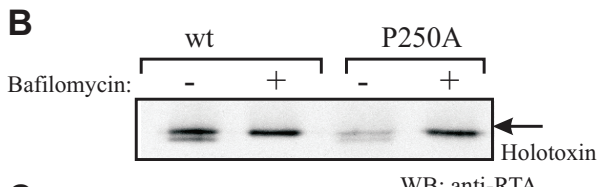

C

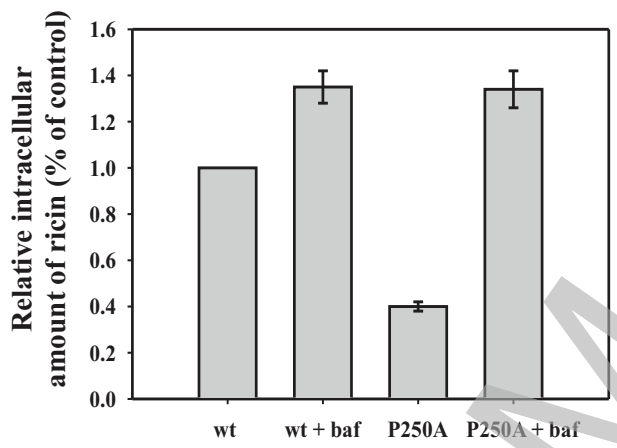

$\mathbf{F}$

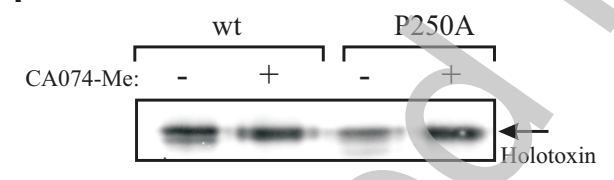

G

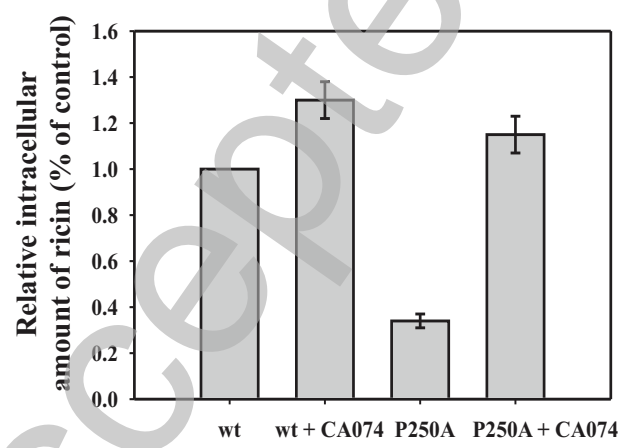

D

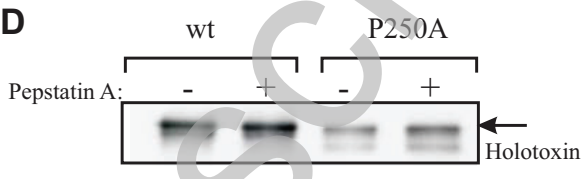

E

WB: anti-RTA

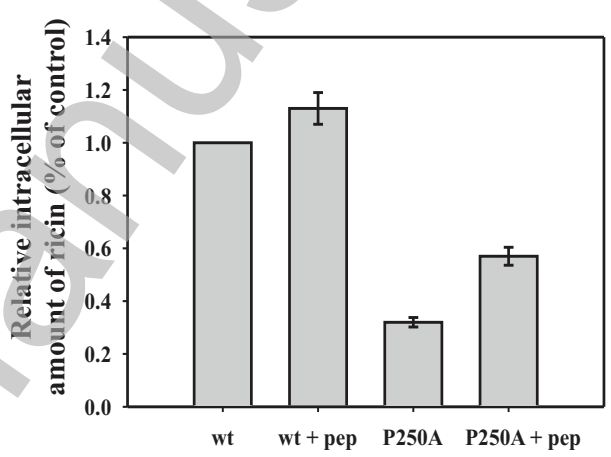

H

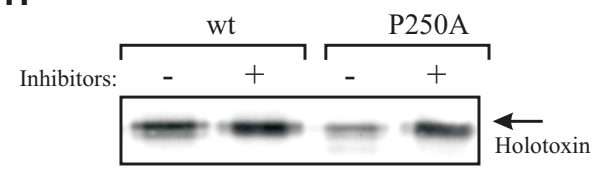

I

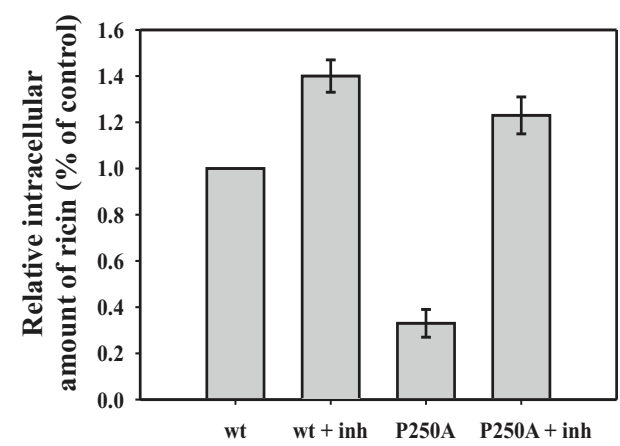

Figure 5

Licenced copy. Copying is not permitted, except with prior permission and as allowed by law. (C) 2011 The Authors Journal compilation (c) 2011 Portland Press Limited 
A

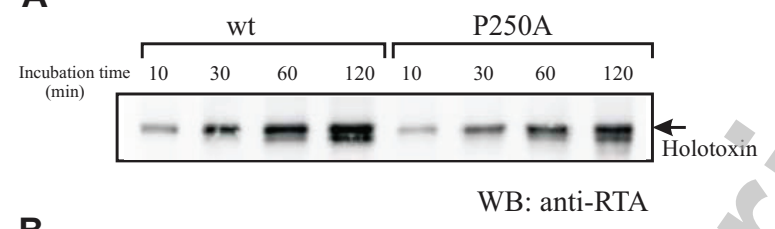

B

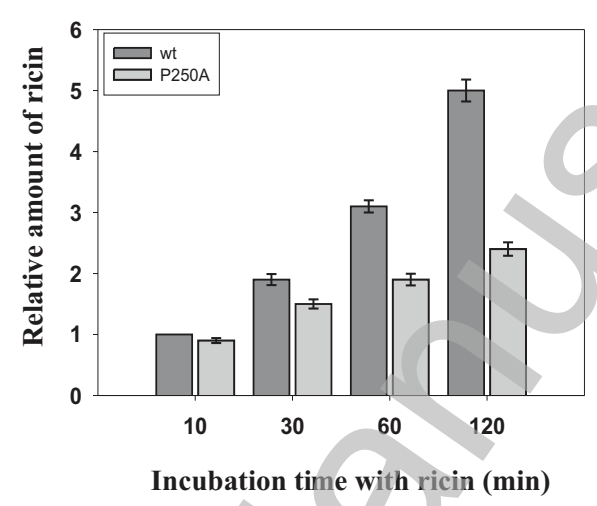

C

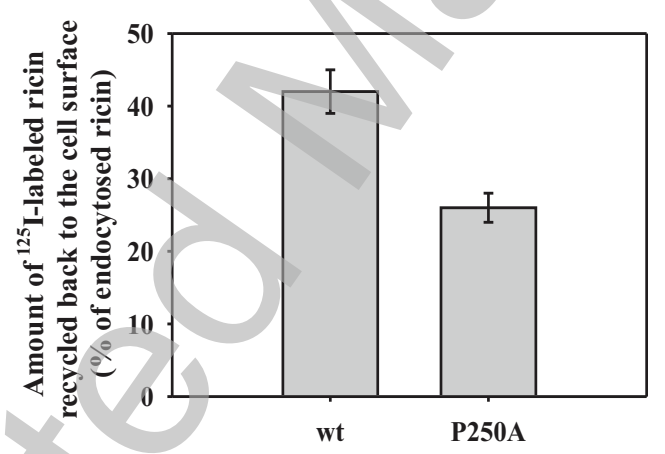

Figure 6 
A

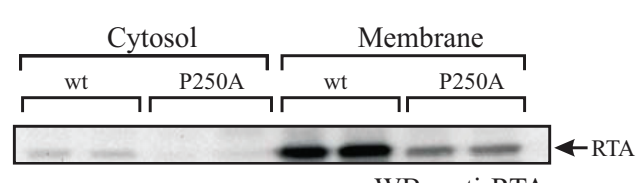

C

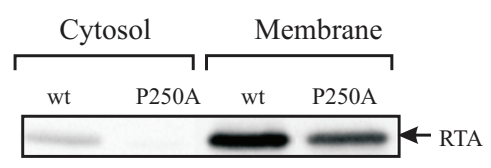

D

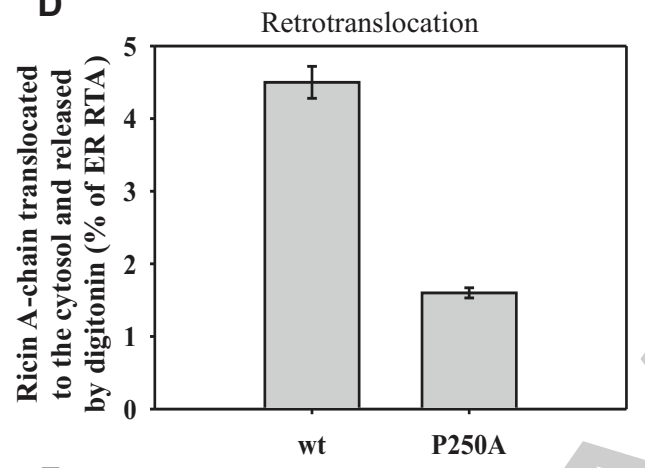

$\mathbf{F}$

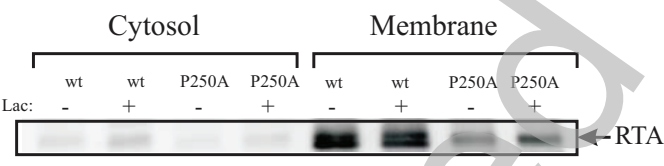

H

$+1$
B

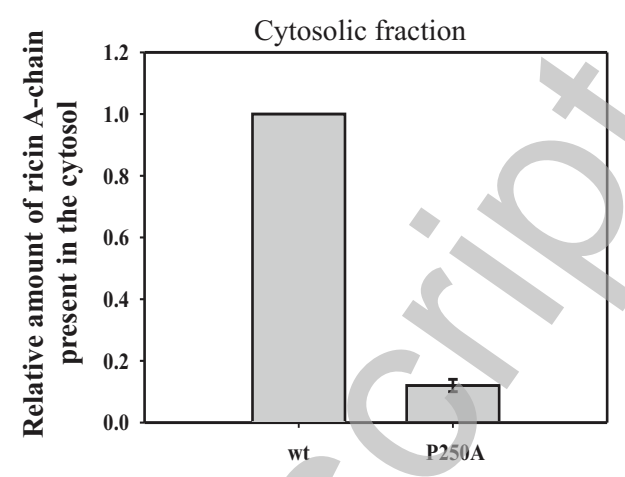

E

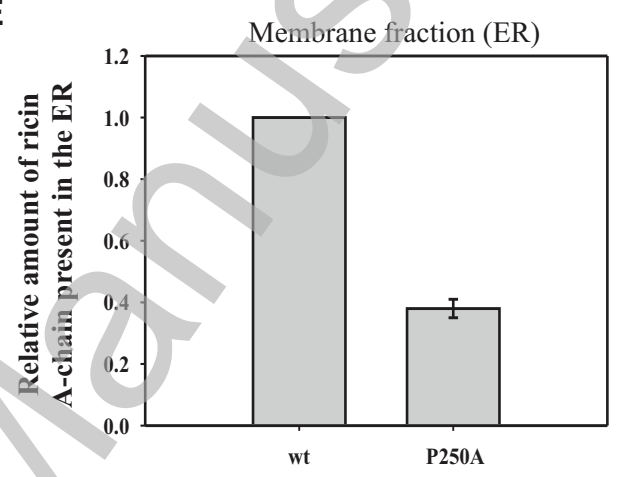

G

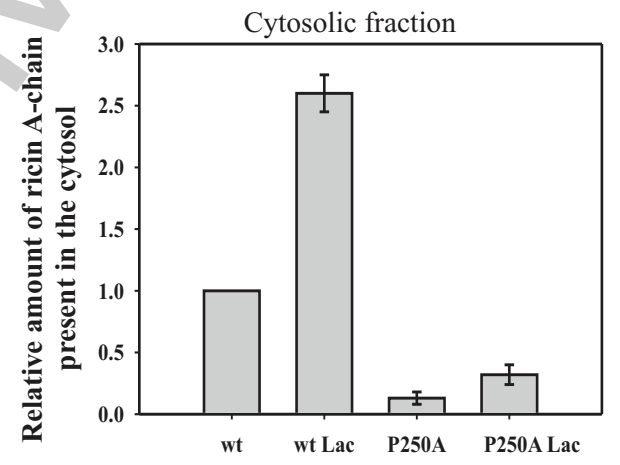

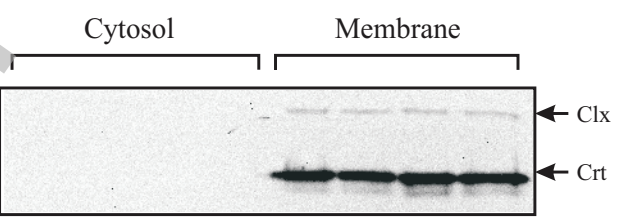

WB: anti-clx, anti-crt

Figure 7

Licenced copy. Copying is not permitted, except with prior permission and as allowed by law. (C) 2011 The Authors Journal compilation (c) 2011 Portland Press Limited 
A

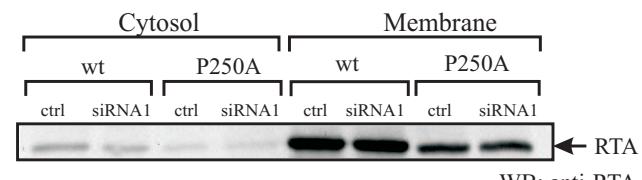

B

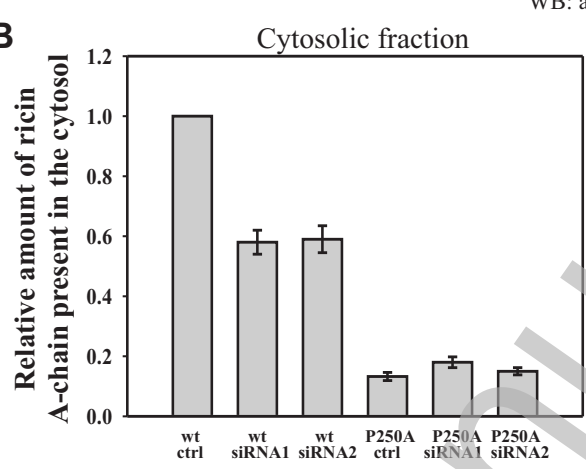

C
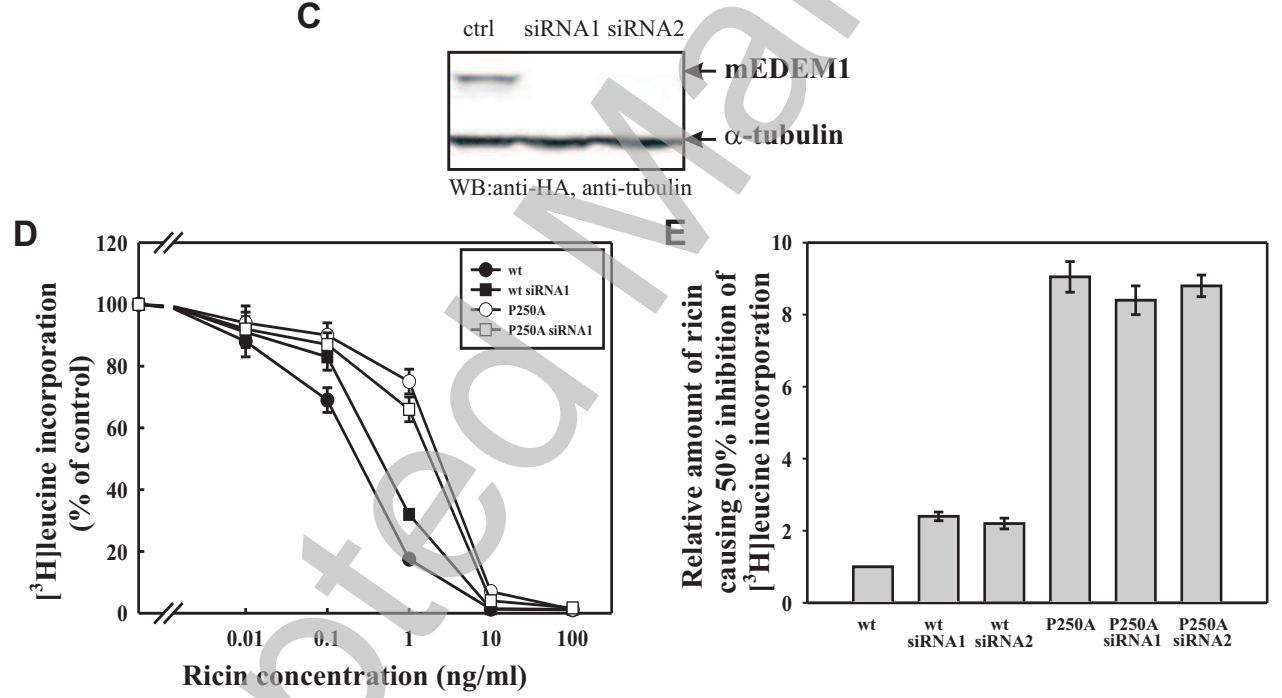

Figure 8 
A

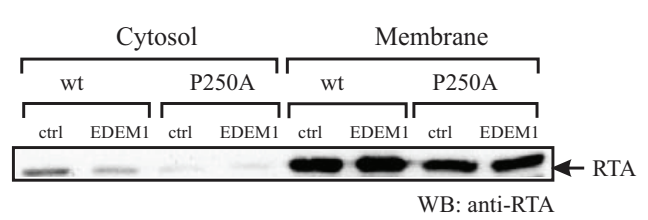

C

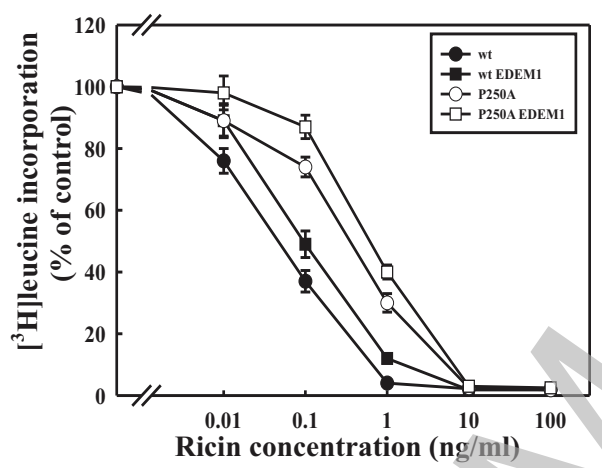

B

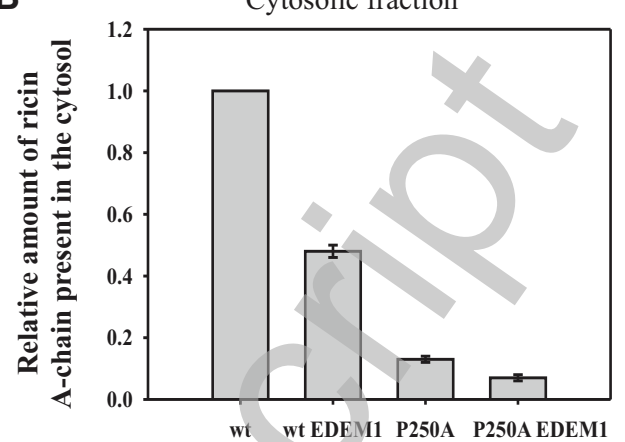

D

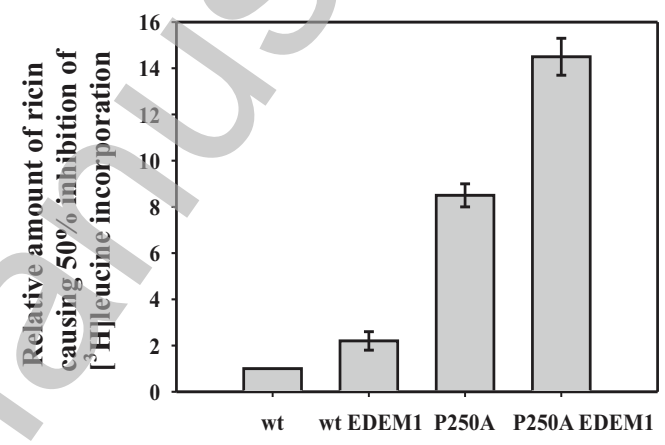

Figure 9 
A

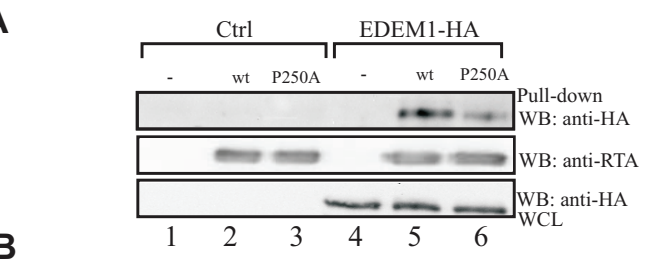

B

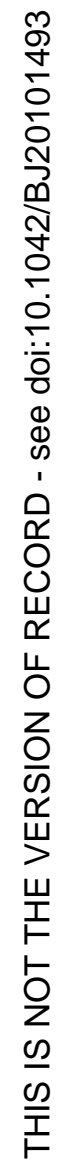

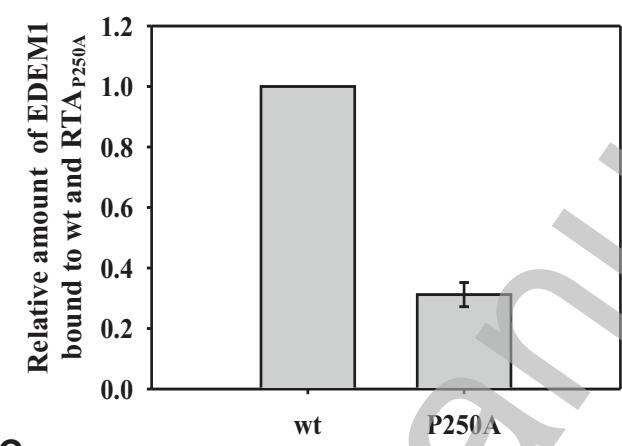

C
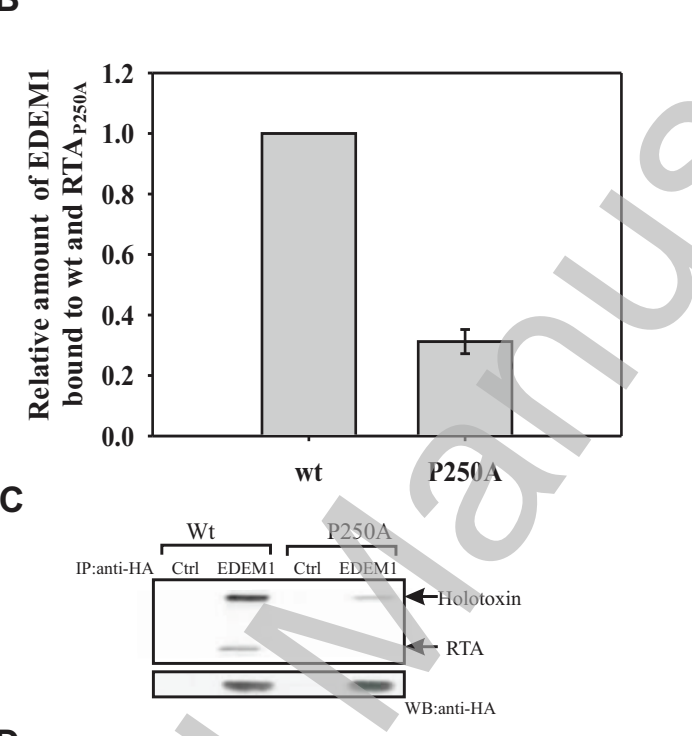

D

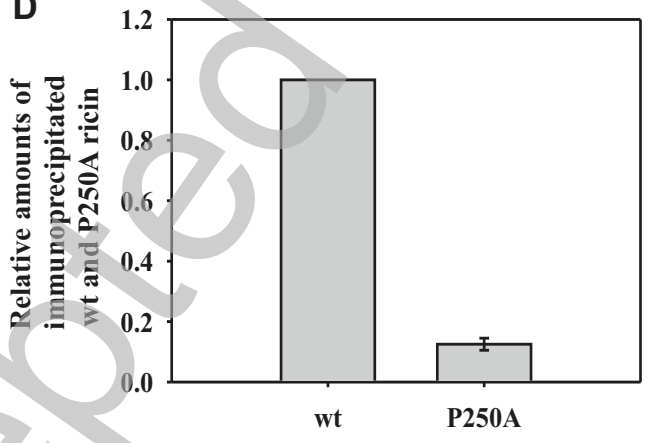

Figure 10 